Georgia State University College of Law

Reading Room

$9-2018$

\title{
Hospital Mergers and Public Accountability: Tennessee and Virginia Employ a Certificate of Public Advantage
}

\author{
Erin C. Fuse Brown \\ Georgia State University College of Law, efusebrown@gsu.edu
}

Follow this and additional works at: https://readingroom.law.gsu.edu/faculty_pub

Part of the Health and Medical Administration Commons, Health Law and Policy Commons, Health Policy Commons, and the Legal Studies Commons

\section{Recommended Citation}

Erin C. Fuse Brown, Hospital Mergers and Public Accountability: Tennessee and Virginia Employ a Certificate of Public Advantage (Milbank Memorial Fund, Sept. 2018). accepted for inclusion in Faculty Publications By Year by an authorized administrator of Reading Room. For more information, please contact mbutler@gsu.edu. 
Milbank Memorial Fund

REPORT

Hospital Mergers and Public

Accountability: Tennessee and

Virginia Employ a Certificate of

Public Advantage

by Erin C. Fuse Brown 


\section{Table of Contents}

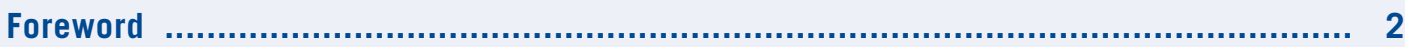

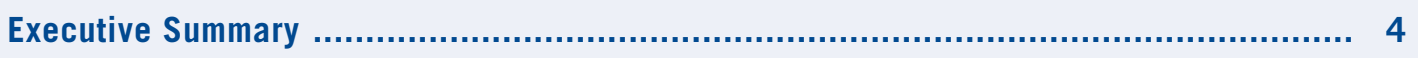

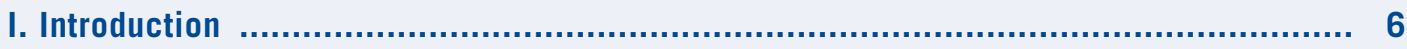

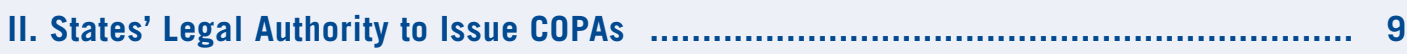

III. Application Process of the Ballad Health COPA ............................................... 15

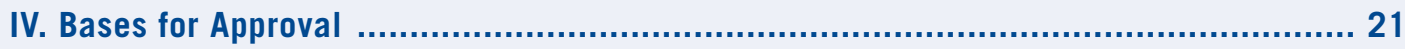

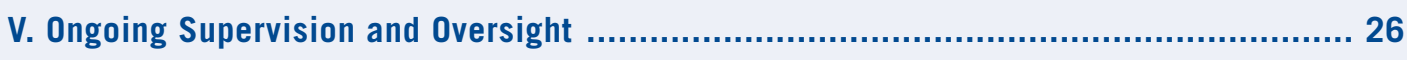

VI. Policy Implications for Other States ............................................................. 30

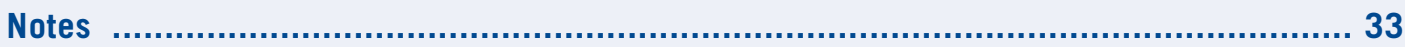

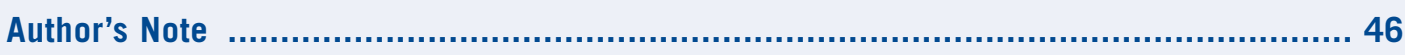




\section{Foreword}

Mergers of all types are going on across the health care system. In some cases, they are horizontal mergers in which the same kinds of entities are coming together. In other cases, they are vertical mergers in which different types of health care entities are coming together.

There are various and sometimes shifting rationales presented by the merging providers-to improve the quality of care, to preserve and grow employment, to build capacity in order to manage the needs of entire populations, or to do more clinical research, gain greater leverage with large payers, or preserve essential community services. Regardless of the "cause," the effect of proposed consolidations poses great challenges to state regulators and policymakers.

These new entities are large and economically and politically powerful institutions. Moreover, in spite of applicant claims, the evidence from hospital consolidations is clear-they raise rather than lower operating costs. Finally, the standards by which mergers are usually evaluated reflect fundamentally conflicting policy desires to see health care as a service that providers compete to provide, and a public good provided by institutions with deep and fundamental public obligations.

These conflicts are heightened when the consolidation results in the creation of a monopoly provider with a significant portion of the services provided. Without reasonable alternatives to the provider, what will be the motivation for the consolidated provider to deliver high-quality medical services at a reasonable price?

State and federal laws can grant state officials the authority to create and oversee such service monopolies through the issuance of a certificate of public advantage (COPA), where the advantage of the monopoly accrues to the public, not the organization. Although never simple to establish and oversee, and not always politically popular, COPAs may be the only alternative states face to denying monopoly-creating provider consolidations.

This report, written by Erin C. Fuse Brown, JD, MPH, from Georgia State University College of Law and the Center for Law, Health, and Society, captures the response to a proposed merger that would create virtually a single hospital provider for a large swath of rural Tennessee and Virginia. The report analyzes the process by which officials in both states developed their COPAs and the resulting standards and enforcement tools. The report also addresses the environment in which the COPA evolved, the application process, the role of each state, and policy implications for other states.

The report raises interesting policy questions:

- First, we can view COPAs in the context of federalism. A new state regulatory scheme evolved as a substitute for federal antitrust scrutiny. Industry advocated for the states to take this on, even if it meant more state regulation. The two states ended up taking more control and responsibility for the processes and outcomes. 
- Unlike the federal authorities that review anti-trust matters, states have multiple roles in overseeing their health care systems. In addition to scrutinizing anti-trust concerns, states are also trying to address hospital closures (particularly in rural areas) and making new investments in population health. A COPA provides a comprehensive way to address these issues.

- A COPA requires a balance between collaboration and regulation. States and health systems need to establish a different relationship blending old and new roles. Is the result of this new relationship an innovative partnership or does it produce conflict and confusion?

- Finally, as illustrated in the report, patients and providers cross state lines-so might oversight standards. When mergers stretch across state boundaries, it can be challenging to mesh pre-existing state laws created over different time frames. By adopting similar COPA laws, two states could more readily coordinate their review and oversight.

State officials will continue to entertain requests from providers to consolidate. A portion of these would create organizations with great economic leverage and concomitant community responsibilities. While it is too early to tell what will happen as a result of the Tennessee-Virginia COPA decisions, state health policymakers and others interested in this field can learn from what has transpired there so far. 


\section{Executive Summary}

Rapid health care consolidation has led to rising health care prices, diminished access to care, and reduced incentives for quality improvement. States have a variety of tools to address these adverse consequences of the loss of health care competition, ranging from state antitrust enforcement to global budgets or provider rate regulation. ${ }^{1}$ One of the tools is a "certificate of public advantage" (COPA), or cooperative agreement, under which the state approves a health care merger and shields it from antitrust enforcement in exchange for state oversight and supervision of the merged entities' conduct. COPAs are controversial. The Federal Trade Commission (FTC) and economists vehemently oppose COPAs, citing evidence that health care consolidation leads to higher prices and does not yield efficiencies, savings, or improved quality. The risks of COPAs are that they create, in essence, a state-sanctioned monopoly that could significantly raise prices, reduce consumer choice and access, and disinvest in essential services that may be less profitable but are critical for population health. Nevertheless, particularly in rural areas, health care providers seek to consolidate to weather mounting financial challenges. In response, states are exploring COPAs as a tool to exercise oversight over the merging parties' health care prices, secure commitments for investments in population health, promote beneficial health care integration, and maintain access to rural health care providers.

This report describes the twin COPAs approved by Tennessee and Virginia in 2017 to allow health systems, Wellmont Health System and Mountain States Health Alliance, to merge to form Ballad Health System, a combined entity that holds a near-monopoly in southwest Virginia and northeast Tennessee. This report highlights the unique features of the Ballad Health COPA, involving two states' COPA laws, and describes the legal authority, factors and commitments secured for approval, and the states' resources and coordination for ongoing supervision. It remains to be seen whether the states can implement the COPAs with sufficient rigor and oversight to ensure the benefits of COPAs outweigh their risks. Several key observations emerge from the Tennessee-Virginia COPA:

- COPAs are resource-intensive. Sufficient resources are essential for states to have the capacity to engage in the rigorous review, approval, and ongoing oversight necessary for a COPA to meet legal requirements and to constrain the merger's anticompetitive harms. Tennessee's and Virginia's laws illustrate the importance of being able to charge the merging parties for all the expenses of the state's application review and oversight.

- COPAs can be a tool to support population health and rural hospitals. COPAs may be most attractive to states under pressure from rural providers seeking mergers to improve their financial status. Meanwhile, states may view population health and maintenance of rural hospitals as the driving factor for approving a COPA. COPAs can provide states with leverage to secure binding commitments from private parties to invest in and assume responsibility for the region's population health. States may be more interested in allowing consolidation among rural providers if the larger health system will support struggling rural hospitals and commit to maintaining the region's access to key service lines. 
- In a multi-state COPA, coordination is key. Tennessee and Virginia saw the importance of coordinating their review and oversight to avoid negative spillover effects on the other state. The health-related and financial fortunes of the region rise and fall together, so the importance of multi-state collaboration and oversight are critical. In addition, coordination is necessary to maintain consistency between the states' conditions and measures for reporting.

- States must balance specificity and flexibility in COPA conditions. The state needs to balance its desire for COPA specificity at the outset with flexibility to make needed adjustments in the future, all while guarding against efforts by the providers to dilute or avoid compliance with COPA conditions in ways that will harm the communities they serve.

- States must define what a successful COPA looks like. States need to be able to assess, on an ongoing basis, whether a COPA is working as a policy matter. Some measures of success may include: (a) no closures of rural facilities; (b) maintenance or improvement of access to key health services; (c) increases in prices and overall health spending in line with comparable markets with more competition; (d) population health improvement among key metrics; and (e) clinical integration via common electronic health records, IT infrastructure, common clinical standards, and regionalization of clinical services. Failure on any of these global measures of COPA performance should trigger an assessment of whether the COPA conditions should be adjusted, whether the state needs to do more to meet its oversight and enforcement obligations, or whether the COPA should be terminated.

- COPAs are risky, and states must remain vigilant. States that pursue COPAs face several risks and challenges. First, the COPA party will have strong incentives to escape stringent regulatory oversight under the COPA. Second, once a merger is consummated, it is extremely difficult to "unscramble the eggs" and force a separation that restores competition among the parties, underscoring the importance of a detailed and updated plan of separation to try to maintain structural separation as a viable remedy. Third, when the state grants a monopoly, it is embarking on a long-term commitment to supervision and must budget for the resources and capacity to engage in rigorous oversight in perpetuity. Fourth, states must collect robust data on prices, access, population health, and quality to fulfill their statutory duties of ensuring the COPA offers a continued net public benefit while constraining the negative effects of consolidation. Finally, even with rigorous oversight the entity may not be financially sustainable, posing the risk that conditions will be worse, not better, than before the merger.

In sum, COPAs are a risky policy solution because they permit health care mergers that would not pass antitrust scrutiny and may result in untenable price increases and other adverse effects. On the other hand, COPAs may offer potential benefits in terms of population health and access particularly for struggling rural communities. Stringent, 
well-resourced, and long-term state oversight is key to avoiding the risks of monopoly and enforcing the commitments to population health and cost control. Whether states can prevent the adverse outcomes and reap the potential benefits under a COPA remains an open question, but Tennessee and Virginia are poised to try.

\section{Introduction}

States face critical financial challenges from rising health care costs and population health challenges in rural areas. Rising health care costs strain state budgets and squeeze resources of businesses and individuals, while rural areas struggle to maintain health facilities and access to providers. ${ }^{2}$ States are seeking tools to control rising health care costs while simultaneously supporting rural health care providers, which are often the largest employers as well as the source of health care services in the region.

Meanwhile, health care payment reforms have spurred a wave of industry consolidation. Providers argue that consolidation is necessary to achieve the scale and scope needed to assume greater financial risk in the shift to value-based payment, to invest in information technology infrastructure, and to take on population health improvement. As a result of widespread consolidation, hospital market concentration in the United States has increased by $40 \%$ in the past 30 years. ${ }^{3}$ No hospital market in the United States remains "highly competitive," nearly half of all hospital markets in the nation are "highly concentrated," and most rural areas struggle to support even one major health care provider, let alone multiple competitors. ${ }^{4}$ As competition diminishes, prices rise because monopoly providers are able to negotiate with payers on an all-or-nothing basis, and payers lose the ability to walk away from negotiations with dominant providers when building their provider networks.

Health care consolidation is frequently justified by the potential of integration to improve health care quality and efficiency. ${ }^{5}$ There is a difference, however, between integration and consolidation. Health care integration occurs when disparate providers become connected clinically, via common electronic health records and shared clinical standards, to coordinate care for a given population of patients. Consolidation involves combining disparate providers and suppliers under common corporate ownership through merger or acquisition, which often increases the market power of the combined entity when negotiating with payers or suppliers. And consolidation is not the only way to achieve health care integration. Independent providers may achieve many of the goals of integration-such as participating in a regional health information exchange or forming an accountable care organizationthrough contractual agreement or joint venture, without corporate consolidation. ${ }^{6}$

Not only are health care integration and consolidation not synonymous, but they also are often at odds with each other. Integration is often considered beneficial for improving patient care and reducing waste, whereas consolidation can generate market power that 
increases prices and reduces consumer/patient welfare. Empirical evidence shows that health care market consolidation significantly increases prices without offsetting improvements in quality or efficiency. Horizontal hospital consolidation leads to $20 \%$ to $40 \%$ higher prices, with greater price increases in concentrated markets. ${ }^{7}$ Monopoly hospitals have $12.5 \%$ higher prices than hospitals in markets with four or more competitors and are better able to resist risk-based contracts that shift financial risk from private payers to providers. ${ }^{8}$ Vertical acquisitions of physician practices by hospitals also leads to higher hospital prices, nearly $14 \%$ higher physician prices, and $10 \%$ to $20 \%$ higher total expenditures per patient. ${ }^{9}$ Despite mounting evidence that consolidated providers raise prices, there is a lack of empirical data illustrating that integration improves quality or reliably generates cost savings through reduced utilization or improved efficiency, undercutting the usual justifications supporting consolidation. ${ }^{10}$

In sum, health care markets are rapidly consolidating, and consolidated providers in concentrated markets raise prices without creating improvements in quality. Nevertheless, particularly in rural areas, states are also contending with the closure of rural hospitals, ${ }^{11}$ bleak population health statistics, and unmet health needs exacerbated by the opioid epidemic. States are therefore seeking tools to allow health system integration to support their rural health care infrastructure and direct resources toward population health, while controlling the adverse effects of consolidation on health care costs, quality, and access. States have a variety of policy tools from which to choose to address rising health care costs, and COPAs are but one. These tools are highlighted in Box 1.

\section{Box 1: States' Policy Tools to Control Health Care Costs from Consolidation}

- Market-based approaches: price transparency, reference pricing by state purchasers

- State antitrust enforcement: merger review, challenging anticompetitive mergers and practices

- Reducing barriers to entry for competitors: eliminating or amending certificates of need, expanding scope of practice laws, telehealth

- Certification and supervision of integrated providers: certificates of public advantage (COPAs), accountable care organization (ACO) certification

- Insurance regulation: strengthening insurance rate review, restricting anticompetitive contracting practices

- Rate oversight and regulation: rate oversight commission, rate caps, site-neutral payment, all-payer rate setting, global budgets

Source: Erin C. Fuse Brown, State Strategies to Address Rising Health Care Costs

Caused by Health Care Consolidation (Washington, DC: National Academy for State Health Policy, Sept. 2017), HTTP://nashp.org/wp-content/uploads/2017/09/Consolidation-Report.pdf. 
Although COPAs are not without controversy, states may find them an attractive tool where struggling rural providers seek merger partners to avoid closure. In this context, states may look to COPAs to support rural providers, promote integration, control excessive price increases, and extract community investment from providers. States can facilitate clinical integration and retain oversight over a monopoly health system by immunizing merging health care entities from federal antitrust enforcement through use of state action immunity. At least 13 states have legislative authority to immunize health care entities from antitrust enforcement-three via state action immunity and 10 via health-related COPAs. ${ }^{12}$ In exchange for antitrust immunity, consolidating entities agree to ongoing oversight and restrictions of their potentially anticompetitive behavior, such as price increases, future acquisitions, or payer contracting practices. COPAs can be risky however. The FTC has expressed strong reservations about COPAs, raising concerns that rather than being necessary to encourage pro-competitive integration, the immunity will only "immunize precisely the types of conduct most likely to cause harm." 13

Although states may be considering COPAs to counteract the effects of health care consolidation, there are few historical examples to learn from. The three most recent examples of mergers approved under state COPAs were in Montana (Benefis Health System, 1996), North Carolina (Mission Health, 1995), and West Virginia (Cabell Huntington/St. Mary's, 2016). In a case study of the Mission Health COPA in North Carolina, the authors noted there was insufficient evidence whether that 20-year COPA effectively counteracted the loss of competition in the area, but they concluded that COPAs may be an underused resource to gain "light-handed, targeted" oversight over otherwise unregulated postconsolidation activities of integrated providers. ${ }^{14}$ Perhaps serving as a cautionary tale rather than as a model, in 2015 North Carolina rescinded its COPA statute, leaving the Mission Health system with monopoly power in the Asheville area, but without state oversight. ${ }^{15}$ Similarly, Montana approved a merger pursuant to its COPA law, and then repealed the COPA law after 10 years, leaving the health system's monopoly intact, but unsupervised. ${ }^{16}$

In late 2017, Tennessee and Virginia approved the cooperative agreement allowing the merger of Wellmont Health System and Mountain States Health Alliance to form Ballad Health, a single health system that holds a near-monopoly in eastern Tennessee and southwestern Virginia. The Ballad Health COPA was unique for a couple of reasons. First, it was larger in scope than prior state COPAs, involving the merger of two health systems that included 19 hospitals across 21 counties in Tennessee and Virginia. ${ }^{17}$ Second, the merger spanned two states, involving the approval and supervision of both states' COPA requirements. Contrast this with a COPA allowing the merger of two hospitals within the same state. ${ }^{18}$ Tennessee's and Virginia's experience with Ballad Health supports the characterization of COPAs as "targeted," but not "light-handed." Indeed, for a COPA to be effective, particularly on the scale of the Ballad Health merger, it may require stringent state oversight of prices, quality, and access that resembles more extensive health care regulatory mechanisms. 
The COPAs in Tennessee and Virginia were driven by the merging parties, who were motivated by both financial and population health challenges. Like many rural providers, Wellmont faced financial challenges and struggled to maintain all its facilities. For example, in 2013 Wellmont closed and subsequently sold 70-bed Lee County Regional Medical Center in Pennington Gap, Virginia. ${ }^{19}$ Wellmont began seeking merger partners and settled on its main rival, Mountain States Health Alliance. ${ }^{20}$ At the time of the merger, neither Tennessee nor Virginia had expanded Medicaid, though Virginia's General Assembly voted in 2018 to approve Medicaid expansion. ${ }^{21}$ State expansion of Medicaid has been shown to improve the financial position of hospitals, reduce the rate of rural hospital closures, and improve access to health care among rural populations. ${ }^{22}$ The regions served by the two systems suffered significantly worse population health than state or national averages across a range of indicators, including smoking rates, obesity, neonatal opiate abstinence syndrome, preventable hospital stays, and primary care and mental health provider ratios. ${ }^{23}$ Against this backdrop, Wellmont and Mountain States negotiated a merger that would result in such a concentration of market power that the parties would need a COPA from both Tennessee and Virginia to avoid antitrust challenge by the FTC. ${ }^{24}$

This report examines a multi-state COPA allowing a merger-to-monopoly to form a large, multi-hospital health system spanning a largely rural or semirural area across two states. Part I introduces the environment in which the Tennessee and Virginia COPAs for Ballad Health occurred. Part II summarizes the states' legal authority to approve the merger under their respective COPA/cooperative agreement laws. Part III describes the Ballad Health COPA application process, including how the application changed over time and the views of the FTC, the public, and other stakeholders submitted through public comments. Part IV details the bases for Tennessee's and Virginia's approvals of the Ballad Health COPA. Part V describes the roles, coordination, and resources of each state in the ongoing active supervision of the Ballad Health COPA. Part VI concludes with policy implications for other states considering COPAs as a tool for regulatory oversight of consolidating health care entities.

\section{States' Legal Authority to Issue COPAs}

The primary legal tool to prevent anticompetitive effects of consolidation are the antitrust laws. At the federal level, the FTC and the Department of Justice (DOJ) enforce the Clayton Act and the Sherman Act, federal antitrust laws that prohibit anticompetitive mergers, collaborations, and conduct. ${ }^{25}$ State attorneys general have parallel antitrust enforcement authority under federal and state antitrust laws to promote and protect competition from anticompetitive mergers or practices. ${ }^{26}$

States can shield otherwise anticompetitive mergers from antitrust enforcement through "state action immunity," in which the challenged conduct is taken pursuant to "a clearly articulated and affirmatively expressed state policy" and is "actively supervised by the 
state." 27 To grant state action immunity for a merger, the state must use a detailed regulatory process that assesses whether the benefits of the merger outweigh the harms resulting from the loss of competition. ${ }^{28}$ This regulatory process is established through laws allowing states to assess the proposed cooperative agreement and grant a COPA to immunize the health care merger from federal antitrust scrutiny in exchange for continued oversight over the merging entity's actions, particularly its prices, but also its quality, accessibility, utilization, and population and community health improvements.

Although there are many similarities between Tennessee's and Virginia's legal authority to approve and oversee COPAs, there are some key differences, set forth in Table 1.

Table 1. Comparison of Tennessee and Virginia COPA Authority

\begin{tabular}{|c|c|c|}
\hline Legal Authority & Tennessee (TN) & Virginia (VA) \\
\hline $\begin{array}{l}\text { What the merger approval is } \\
\text { called }\end{array}$ & COPA & Cooperative agreement \\
\hline Scope of COPA authority & All of TN & Southwest VA only \\
\hline $\begin{array}{l}\text { Reviewing and approving } \\
\text { officials/agencies }\end{array}$ & $\begin{array}{l}\text { One level of review: commis- } \\
\text { sioner of Tennessee Depart- } \\
\text { ment of Health (TDH) }\end{array}$ & $\begin{array}{l}\text { Two levels of review: South- } \\
\text { west VA Health Authority } \\
\text { makes a recommendation, } \\
\text { commissioner of VA De- } \\
\text { partment of Health (VDH) } \\
\text { makes an independent } \\
\text { determination of approval }\end{array}$ \\
\hline $\begin{array}{l}\text { State attorney general's } \\
(\mathrm{AG}) \text { role }\end{array}$ & $\begin{array}{l}\text { TDH commissioner } \\
\text { required to obtain TN AG's } \\
\text { agreement to approve } \\
\text { TN AG actively involved in } \\
\text { review }\end{array}$ & $\begin{array}{l}\text { VDH commissioner required } \\
\text { to consult with VA AG, but } \\
\text { little coordination in review }\end{array}$ \\
\hline $\begin{array}{l}\text { Whether agency can accept } \\
\text { confidential submissions } \\
\text { from applicants }\end{array}$ & $\begin{array}{l}\text { TDH is unable to accept } \\
\text { confidential submissions } \\
\text { TN AG can accept confiden- } \\
\text { tial information }\end{array}$ & $\begin{array}{l}\text { VDH can accept confidential } \\
\text { submissions }\end{array}$ \\
\hline Standard for approval & $\begin{array}{l}\text { Clear and convincing } \\
\text { evidence }\end{array}$ & Preponderance of evidence \\
\hline
\end{tabular}




\begin{tabular}{|c|c|c|}
\hline Criteria for review & $\begin{array}{l}\text { TDH to consider "other } \\
\text { benefits" } \\
\text { (See Table 2.) }\end{array}$ & $\begin{array}{l}\text { VDH to consider participa- } \\
\text { tion in Medicaid programs, } \\
\text { total cost of care } \\
\text { (See Table 2.) }\end{array}$ \\
\hline Legal Authority & Tennessee (TN) & Virginia (VA) \\
\hline Conditions for approval & $\begin{array}{l}\text { TDH's conditions for ap- } \\
\text { proval are subject to agree- } \\
\text { ment between TDH and the } \\
\text { parties }\end{array}$ & $\begin{array}{l}\text { VDH commissioner may } \\
\text { condition approval on } \\
\text { applicants' commitments to } \\
\text { achieving specified improve- } \\
\text { ments in population health, } \\
\text { access to health care } \\
\text { services, quality, and cost } \\
\text { efficiencies. }\end{array}$ \\
\hline Form of approval & $\begin{array}{l}\text { Terms of certification, } \\
\text { structured like a contract, } \\
\text { subject to COPA parties' } \\
\text { agreement }\end{array}$ & $\begin{array}{l}\text { Order, structured like a } \\
\text { consent decree; conditions } \\
\text { not subject to agreement by } \\
\text { the parties }\end{array}$ \\
\hline Oversight authority & TDH and TN AG & VDH commissioner \\
\hline $\begin{array}{l}\text { Entity charged with } \\
\text { oversight }\end{array}$ & $\begin{array}{l}\text { COPA monitor (private } \\
\text { contractor) }\end{array}$ & VDH staff \\
\hline Enforcement authority & $\begin{array}{l}\text { TDH, TN AG (each has inde- } \\
\text { pendent authority to enforce } \\
\text { COPA) } \\
\text { Penalties/remedies: Seek } \\
\text { modification of COPA with } \\
\text { parties' consent, limit pay- } \\
\text { ment of executive incentive } \\
\text { compensation, impose fines, } \\
\text { termination }\end{array}$ & $\begin{array}{l}\text { VDH commissioner only } \\
\text { Remedies: Seek modifica- } \\
\text { tion of cooperative agree- } \\
\text { ment with consent of the } \\
\text { parties, termination }\end{array}$ \\
\hline $\begin{array}{l}\text { Fees for review and ongoing } \\
\text { oversight }\end{array}$ & $\begin{array}{l}\text { COPA applicants responsible } \\
\text { for all costs of TDH and TN } \\
\text { AG review and ongoing } \\
\text { supervision, including } \\
\text { outside consultants and } \\
\text { experts }\end{array}$ & $\begin{array}{l}\text { At the time of approval } \\
\text { (2017), VDH only able to } \\
\text { charge applicants } \$ 75,000 \\
\text { for review and up to } \\
\$ 75,000 \text { annually for ongo- } \\
\text { ing supervision } \\
\text { In } 2018, \text { VA passed a law } \\
\text { allowing VDH to charge } \\
\text { COPA parties for all rea- } \\
\text { sonable costs of review and } \\
\text { ongoing supervision, includ- } \\
\text { ing outside consultants and } \\
\text { experts }\end{array}$ \\
\hline
\end{tabular}




\section{A. Tennessee}

Tennessee law ${ }^{29}$ permits the state to issue a COPA to "displace competition among hospitals with regulation ... and actively supervise that regulation ... to promote cooperation and coordination among hospitals in the provision of health services and to provide state action immunity from federal and state antitrust law ... to those hospitals issued a certificate of public advantage." 30

To obtain a COPA, the merging hospitals must submit an application to the Tennessee Department of Health (TDH) and state attorney general detailing the terms of the merger agreement, called a "cooperative agreement," as well as supplemental materials about the parties' financials, service areas, payer contracts, and other documentation addressing the COPA criteria. ${ }^{31} \mathrm{TDH}$ reviews the application, conducts public hearings, and consults with and obtains the agreement of the attorney general to determine whether to approve the application and issue the COPA.

Tennessee's COPA application requirements are extensive, including submission of the parties' signed cooperative agreement, financial statements, budgets, and detailed descriptions of its service areas, costs, policies, and how the parties anticipate meeting requirements for access, quality, costs, savings, and efficiencies. ${ }^{32}$ Of note, the applicant must submit and annually update its plan of separation. ${ }^{33}$ One of the main critiques of COPAs is that it is difficult to undo a consummated merger for practical and regulatory reasons, even if it fails to generate the anticipated advantages (efficiencies, savings, or quality) or worse, if it allows the entity to raise prices and reduce access to or availability of services. ${ }^{34}$ Owing to the difficulty of "unscrambling the eggs," the COPA application's requirement of a detailed and updated plan of separation attempts to maintain as a viable option the return of the parties to a separated state in the event of the termination of the COPA, like a prenuptial agreement for the merger.

After consulting with and gaining agreement from the state attorney general, TDH may issue the COPA if it determines that the applicants have "demonstrated by clear and convincing evidence that the likely benefits resulting from the Cooperative Agreement outweigh any disadvantages attributable to a reduction in competition that may result from the Cooperative Agreement." ${ }^{35}$ To make its determination, TDH must evaluate certain enumerated benefits and disadvantages. Table 2 describes the statutory criteria for Tennessee and Virginia. ${ }^{36}$ 
Table 2. Statutory Criteria for COPA in Tennessee and Virginia

\begin{tabular}{|c|c|}
\hline Benefits & Disadvantages \\
\hline $\begin{array}{l}\text { 1. Enhancement of the quality of hospital } \\
\text { and hospital-related care provided to } \\
\text { [the state's] citizens }\end{array}$ & $\begin{array}{l}\text { The extent of any likely adverse impact on } \\
\text { the ability of...payors to negotiate appropri- } \\
\text { ate payment and service arrangements with } \\
\text { hospitals, physicians, allied health care } \\
\text { professionals, or other health care providers }\end{array}$ \\
\hline $\begin{array}{l}\text { 2. Preservation of hospital facilities in } \\
\text { geographical proximity to the } \\
\text { communities traditionally served } \\
\text { by those facilities }\end{array}$ & $\begin{array}{l}\text { The extent of any reduction in competition } \\
\text { among physicians, allied health professionals, } \\
\text { other health care providers, or other per- } \\
\text { sons furnishing goods or services to, or in } \\
\text { competition with, hospitals that is likely to } \\
\text { result directly or indirectly from the cooper- } \\
\text { ative agreement }\end{array}$ \\
\hline $\begin{array}{l}\text { 3. Gains in the cost efficiency of services } \\
\text { provided by the hospitals involved }\end{array}$ & $\begin{array}{l}\text { The extent of any likely adverse impact on } \\
\text { patients in the quality, availability, and price } \\
\text { of health care services }\end{array}$ \\
\hline $\begin{array}{l}\text { 4. Improvements in utilization of hospital } \\
\text { resources and equipment }\end{array}$ & $\begin{array}{l}\text { The availability of arrangements that are less } \\
\text { restrictive to competition and achieve the } \\
\text { same benefits or a more favorable balance } \\
\text { of benefits over disadvantages attributable } \\
\text { to any reduction in competition likely to } \\
\text { result from the agreement. }\end{array}$ \\
\hline \multicolumn{2}{|l|}{$\begin{array}{l}\text { 5. Avoidance of duplication of hospital } \\
\text { resources }\end{array}$} \\
\hline \multicolumn{2}{|l|}{$\begin{array}{l}\text { 6. Demonstration of population health im- } \\
\text { provement of the region served according } \\
\text { to criteria set forth in the agreement and } \\
\text { approved by the department }\end{array}$} \\
\hline \multicolumn{2}{|l|}{$\begin{array}{l}\text { 7. Any other benefits that may be identified } \\
\text { (TN only })^{37}\end{array}$} \\
\hline $\begin{array}{l}\text { 8. Participation in state Medicaid program } \\
\text { (VA only) }\end{array}$ & \\
\hline 9. Total cost of care (VA only) & \\
\hline
\end{tabular}

Source: Tenn. Code Ann. § 68-11-1303(e); Va. Code Ann. § 15.2-5384.1(E).

TDH must consult with the state attorney general to evaluate the effects of the reduction in competition from the proposed merger and obtain agreement from the attorney general to issue a COPA. ${ }^{38}$ Unlike TDH, the attorney general's office may accept confidential submissions relating to the COPA, which was useful in the case of the Ballad Health application 
to gather competitively sensitive information from the merging parties. This may lead to greater involvement of the attorney general's office in all phases of review. For the Ballad Health application, the attorney general's office was heavily involved from the outset as part of the team reviewing the application for competitive, economic, and regional effects of the proposed merger. TDH may (but does not have to) consult with federal antitrust enforcement agencies. ${ }^{39} \mathrm{TDH}$ also met with and solicited comments from FTC officials as part of its review of the Ballad Health COPA application.

After a COPA is issued, TDH must review the COPA at least annually to determine whether the likely benefits of the COPA are outweighed by the disadvantages from the reduction in competition. ${ }^{40}$ If it makes such a determination, TDH may seek a modification from the parties or terminate the COPA. Termination of the COPA would trigger the obligation of the health care entity to complete its plan of separation. Upon termination of the COPA, the state supervision required for state action immunity would no longer exist, and the parties could be subject to antitrust enforcement. ${ }^{41}$

\section{B. Virginia}

Clearing a path for the merger of Wellmont and Mountain States, Virginia enacted a law in 2015 authorizing the Virginia health commissioner to approve health care mergers under a cooperative agreement among facilities serving citizens in the Southwest Virginia Health Authority (authority). ${ }^{42}$ Although the Virginia law does not use the term "certificate of public advantage," the effect of approval of the cooperative agreement is the same: it shields the merger from antitrust scrutiny through the application of state action immunity. ${ }^{43}$ It differs from the Tennessee COPA law in that the availability of a cooperative agreement is limited to mergers among health facilities in a particular region of southwest Virginia. ${ }^{44}$

Health care entities in southwest Virginia submit an application for approval of their proposed cooperative agreement to the authority, which provides copies of the application to the commissioner and the Virginia attorney general. ${ }^{45}$ Virginia's application requirements are similar to the requirements in Tennessee. ${ }^{46}$ Nevertheless, there are some differences, such as Virginia's requirements for information on employed physicians, potential market entrants, top 10 commercial payers, and a description of the applicants' commitments to address any adverse impacts of the merger, including proposed metrics and consequences for failing to satisfy the commitment. ${ }^{47}$

In Virginia, the decision whether to approve a cooperative agreement rests with the commissioner of the Virginia Department of Health (VDH). As a preliminary matter, the authority reviews the application and makes a recommendation to the commissioner. ${ }^{48}$ After reviewing the authority's recommendation and the administrative record, and after consultation with the state attorney general, the commissioner "shall approve" the cooperative agreement if he or she independently finds that the benefits of the cooperative agreement outweigh the disadvantages from the reduction of competition. ${ }^{49}$ To make the 
determination, the commissioner considers a list of enumerated benefits and disadvantages that largely mirror those in Tennessee (see Table 2). ${ }^{50}$

The main differences from Tennessee's criteria for approval are, first, Virginia requires consideration of benefits to Medicaid participation and the total cost of care, while Tennessee allows the department to identify "other benefits." Second, Tennessee requires TDH to makes its determination based on "clear and convincing evidence" while Virginia's law requires the commissioner to make a determination by a lower "preponderance of the evidence" standard. ${ }^{51}$ Third, the Virginia health commissioner may condition approval of the cooperative agreement upon the applicants' commitments to achieving specified improvements in population health, access to health care services, quality, and cost efficiencies. ${ }^{52}$ Tennessee's terms and conditions for approval are subject to agreement between TDH and the parties. ${ }^{53}$ Before granting the COPA, the parties and TDH must agree on terms of certification and specific conditions that assure the public advantage.

Virginia's process of review also differs from Tennessee's. Virginia prescribes two levels of review: first by the authority and then by the commissioner. In the case of Ballad Health, the Virginia attorney general's office was less involved in VDH's review of the application than Tennessee's attorney general. Tennessee law requires the attorney general's agreement for TDH to approve a COPA, which in practice meant that Tennessee's attorney general was intimately involved in the review from the start. Virginia's commissioner must consult with the state attorney general but does not have to obtain attorney general approval. In practice, this meant that the Virginia attorney general's office conducted its review independently of the commissioner's office. ${ }^{54}$ Third, unlike Tennessee, where all submission materials are subject to state open records requirements, Virginia's authority and commissioner may accept confidential information from the applicants and make public redacted versions, which may facilitate in-depth economic review of competitively sensitive information without having to go through the state attorney general's office.

\section{Application Process of the Ballad Health COPA}

The states' processes for reviewing the Ballad Health COPA application were both resource-intensive and procedurally robust. This part describes the application process and time line, the ways the application changed between initial submission and approval, and the public comments and expert views considered.

\section{A. Application Process and Timeline}

Wellmont Health System and Mountain States Health Alliance submitted their application for state approval to form Ballad Health via cooperative agreement to the TDH and the Southwest Virginia Health Authority on February 16, 2016.

Over the following 19 months, TDH requested and received supplemental information from the parties at least three times before TDH determined the application complete on 
May 22, 2017. ${ }^{55} \mathrm{TDH}$ held six public hearings and received 15 written public comments (including three comment letters from FTC staff) ${ }^{56}$ before approving the COPA application on September 19, 2017.57

In Virginia, the authority evaluated the application, conducted a joint public hearing with $\mathrm{VDH}$, received public comments, and recommended to the VDH commissioner that the Ballad Health cooperative agreement be approved on November 22, 2016. ${ }^{58}$ The commissioner requested supplemental information twice and met with the parties three times, followed by additional requests for data. ${ }^{59}$ After Tennessee approved the COPA on September 19, 2017, the applicants submitted revised commitments to the authority in Virginia, which provided the commissioner with its feedback on October 16, 2017.60 The Virginia attorney general provided a letter of consultation to the commissioner on October 23, 2017. ${ }^{61}$ The commissioner issued an order approving the cooperative agreement on October 30, 2017, accompanied by a report containing VDH staff analysis, the applicants' revised commitments, and the commissioner's conditions for approval. ${ }^{62}$

Several months into the application review process, TDH and VDH officials and staff involved with the COPA review began collaborating in earnest, including weekly conference calls. Although each state had its own independent duties to evaluate the Ballad Health COPA application, the states found that close coordination enabled more efficient review and allowed the agencies to share information and expert analyses and refine questions for the applicants. This collaboration also benefited the applicants in terms of streamlining information submissions, avoiding duplicative or conflicting information requests, and creating a more unified set of commitments, measures, and reporting requirements for ongoing oversight. The states anticipate continuing to collaborate closely to supervise the COPA, evaluate compliance with legal requirements and conditions, and monitor the public advantage of the Ballad Health merger.

The close collaboration between the states proved critical to the timing of the COPA approvals. Once Tennessee approved the COPA, a great deal of pressure mounted for Virginia to announce its decision, which it did a little more than a month later. Before announcement of Virginia's decision, there was substantial concern that if Virginia did not approve the cooperative agreement, then Ballad Health would continue with the merger among Tennessee facilities but divest the Virginia facilities, which could leave these facilities without the level of state oversight provided by a COPA or the financial and administrative support of the rest of the Ballad Health system. The depth of coordination and information sharing between the states allowed both states' concerns to be addressed and reduced the risk that the states would reach differing conclusions about approval, which could have left the region in a worse position than had both states approved or disapproved the COPA.

The differences between the states' form of approval —-terms of certification versus order and conditions-highlights the unique regulatory character of a COPA approval. COPA approvals may resemble an adjudicatory process akin to a consent decree as well as a 
negotiated agreement. When the state's approval and conditions take the form of an agreement, the COPA parties may believe they have more ability to negotiate with the state COPA authorities over these terms. Virginia's structuring of its approval decision as an "order" with discretion to impose conditions ${ }^{63}$ allows the commissioner broader authority to dictate the terms of the approval than Tennessee's "terms of certification" and requirement to obtain the parties' agreement to the COPA terms, which are structured like a contract and lead parties to approach the state as another counterparty to the merger with which it is negotiating. 64

\section{B. Application Changes from Initial Proposal to Final Approved Version}

The Ballad Health COPA application was voluminous at the outset ${ }^{65}$ but was nonetheless inadequately detailed to satisfy the states' requirements for review. Both states issued several requests for supplemental information, and most of these requests were aimed at soliciting more detailed information to assess competitive, economic, and service-line effects of the proposed merger, including financial projections, more specific financial commitments, details on the parties' employees and health plan contracts, and proposed continued uses and service lines of the merging facilities. Thus, the application evolved over time to become progressively more detailed and more specific. ${ }^{66}$

The application and the parties' commitments also evolved substantively. For example, the parties' proposal to limit the price effects of Ballad Health's monopoly power on private health plans expanded and became more stringent from the initial application to its final approved commitments. ${ }^{67}$ In response to the parties' amended price commitments, VDH staff noted, "The New Health System has committed to significant limitations, beyond what it initially proposed, on its ability to increase the prices it charges to payers." 68 Initially, the applicants had proposed to reduce its private rate increases by $50 \%$ in the first year after the merger and then limit future price increases to the Consumer Price Index (CPI)-hospitals minus $0.25 \%$ for hospital services and CPI-medical minus $0.25 \%$ for physicians and outpatient services. ${ }^{69}$ In its final commitments, the parties agreed to limit price increases to the latest Centers for Medicare and Medicaid Services (CMS) Medicare Market basket amount plus $0.25 \% .^{70}$ The initial application proposed limiting rate increases only for "principal payers," defined as commercial payers that make up more than $2 \%$ of the new health system's total net revenues. ${ }^{71}$ The final approved commitments applied price limitations to all payers, including small commercial payers, Medicare Advantage, and Medicaid payers. ${ }^{72}$

The second example was the parties' financial commitments to invest sums toward expanded access to health services, population health improvement, graduate medical education, and a regional health information exchange. Initially, the parties' application proposed to use anticipated cost savings to fund these health-related investments. ${ }^{73}$ Although the total financial commitments ( $\$ 308$ million) were unchanged in the final approved version, the nature of the financial commitments became more specific, and, 
significantly, the final commitments were not contingent upon the parties generating cost savings from the merger. ${ }^{74}$

A third example was that population health outcomes were initially to be based solely on the parties' own patients rather than the broader population of residents in the geographic area. In the final agreement approved by Tennessee, the population health measures are to be based on the entire population in the geographic service area covered by the cooperative agreement. $^{75}$

In all of these instances, the states insisted upon more stringent conditions for the merging parties and a greater benefit to the population as a whole.

\section{Expert Views and Public Comments}

Both states received public comments from governmental organizations, economists, community groups, and members of the general public. This section highlights the concerns of some of the commenters, particularly the views of the FTC, academic experts and economists, health plans, and community stakeholder groups.

\section{Views of the Federal Trade Commission}

The FTC submitted three comments to TDH and VDH regarding the COPA application based on a year-long assessment of the Ballad Health merger. ${ }^{76}$ The FTC comments were highly detailed and totaled more than 170 pages. In sum, the FTC's position was this: "If the COPA is approved, the harm resulting from the reduction in competition is likely to far outweigh any potential benefits. In our view, the evidence put forward by the parties in their COPA application falls far short of the 'clear and convincing' standard they must meet pursuant to the Tennessee Hospital Cooperation Act. Consequently, we urge the Department not to approve the COPA." 77 To support its conclusion, the FTC made the following arguments.

First, the FTC provided quantitative evidence that Wellmont and Mountain States are each other's closest competitors, and allowing them to merge would result in a near-monopoly in inpatient and certain outpatient services in the area. ${ }^{78}$ The level of concentration after merger would be so high as to create a "presumption of illegality."79 This reduction in competition would lead to higher prices, reduced competition, reduced incentives for quality, and worse accessibility and availability of services. ${ }^{80}$ Competition between the merging parties has previously created incentives for the parties to compete for patients based on quality and service lines, and "the threat of losing patients and physician referrals to a rival system incentivizes each system to provide the best possible quality and patient experience."81 
Second, the FTC was highly skeptical of the parties' claimed benefits from the COPA, noting that they would not outweigh the merger's likely disadvantages. The FTC noted that many of the investments in health information exchange or electronic health records and community or population health initiatives could be achieved with contractual arrangements and joint ventures less harmful to competition.

Third, the FTC was doubtful that the parties' proposed commitments would mitigate the harmful effects of the merger. For example, the FTC noted that the parties' initial commitments to make community investments were contingent on the applicants achieving their cost-saving targets. ${ }^{82}$ FTC staff also noted that price and quality commitments are difficult to administer and enforce. ${ }^{83}$ In addition, the FTC pointed out weaknesses in the parties' commitments that would undermine their effectiveness: the commitment to maintain operation of rural hospitals is only effective for five years; the price caps for private payers would not apply to value-based or risk-based contracts; and the exclusion of payers with less than $2 \%$ of the health system's net revenues would exempt 200 payers from the system's price commitments. ${ }^{84}$ Some of these concerns were addressed in the final set of conditions imposed by the states.

Fourth, the FTC noted that the parties' proposed plan of separation would not be an effective remedy to restore competition in the event of the termination of the COPA. Noting the practical difficulties of unwinding consummated mergers, or "unscrambling the eggs," the FTC was concerned that the parties' proposed plan of separation was inadequate, instead simply proposing a process to develop a plan of separation based on the market conditions at the time, which would not meaningfully restore a pre-consolidation state of competition. ${ }^{85}$

Finally, the FTC noted the challenges that other states have faced "regulating a hospital monopoly in perpetuity" under state COPAs. It highlighted how legislative repeal of North Carolina's and Montana's COPA laws meant that hospital monopolies approved in those states under a COPA were now virtually unregulated. ${ }^{86}$

In addition to advising the rejection of the COPA application, the FTC's comments and analyses served another important role: they signaled to the COPA applicants that the FTC could and perhaps would likely pursue enforcement to block or seek to unwind the merger in the absence of the COPA. The unfavorable views of the FTC, though at odds with the states' ultimate approvals of the COPA, actually strengthened the hand of the states. The threat of FTC antitrust enforcement can motivate the parties to accept and comply with the state COPA authorities' stringent conditions for approving the COPA, because if the states disapprove the COPA, then the FTC has indicated it would block the proposed merger. The FTC's concerns also highlight the importance of stringent state oversight in perpetuity and the maintenance of a detailed and viable plan of separation. 
Despite the FTC's disagreement with the ultimate approval of the COPAs, the states actively sought the FTC's input in their review. Viewing the FTC as a partner and a resource, particularly for an economic and market-based analysis of the merger's competitive effects, allowed the states to seek additional refinements to the conditions imposed on the COPA parties.

\section{Views of Academic Economists and Health Insurance Plans}

The views of the FTC were echoed in the comments submitted by academic experts, economists, and health insurance plans. ${ }^{87}$ Most of the economists who submitted comments urged the states to reject the COPA application, citing evidence that hospital mergers lead to higher prices and reductions or lack of improvements in quality. The economists expressed doubt that the states could effectively monitor or enforce postmerger conduct after granting the Ballad Health monopoly, due to the complexity, resource intensity, and difficulty calculating and updating performance measures. ${ }^{88}$

TDH also received comments from representatives of health insurance plans, trade group America's Health Insurance Plans (AHIP), and health plans Amerigroup and Anthem Blue Cross Blue Shield of Virginia. AHIP commissioned an economic analysis to assess the competitive impact of the merger of the parties' acute care hospitals. ${ }^{89}$ AHIP's experts concluded that the merger is likely to "significantly reduce competition and raise prices for consumers," consistent with the findings of the FTC. ${ }^{90}$ Amerigroup is a health plan offering Medicare Advantage and Medicaid managed care plans to approximately 400,000 individuals in Tennessee, including residents in the area affected by the merger. Amerigroup similarly objected to the Ballad Health merger, arguing that the parties understated the competitive risks of the merger and that their proposed commitments would not result in the claimed benefits. ${ }^{91}$ In particular, it expressed concern that the parties' initial price limitations did not apply to Medicare Advantage or Medicaid managed care payers. ${ }^{92}$ Anthem Blue Cross Blue Shield of Virginia submitted a similar comment to the authority in Virginia ${ }^{93}$ and argued that the merger "would result in a monopoly hospital system....and even the oversight proposed by this Cooperative Agreement Application would be inadequate to ensure low prices and high quality health care in southwest Virginia." 94

\section{Views of Community Stakeholder Groups}

TDH received comments from the Bristol, Johnson City, and Kingsport chambers of commerce urging approval of the merger, citing concerns that allowing either applicant to merge with other entities would lead to higher prices and greater loss of jobs in the area. ${ }^{95}$ The Holston Medical Group, a large, multispecialty group serving the area, also supported approval of the merger "if properly regulated" due to investments in the regional health information exchange and limits on physician employment. ${ }^{96}$ Most of the individuals who commented, however, expressed opposition to the merger, citing the adverse effects on consumers' health care prices, choices, and access in the area. ${ }^{97}$ 


\section{Bases for Approval}

Tennessee issued a letter approving the Ballad Health COPA on September 19, 2017,,98 and Virginia approved the cooperative agreement a little more than a month later, on October 30, 2017. ${ }^{99}$ In their letters of approval, both Tennessee and Virginia cited the bleak population health statistics, regional economic factors, and health care delivery system challenges in the geographic area served by the merging health systems. Noting that competition between Wellmont and Mountain States was not resulting in meaningful health benefits in terms of access or health outcomes, the commissioners in each state viewed the COPA process as a vehicle to secure substantial commitments from Ballad Health for population health improvements, infrastructure and workforce investments, and keeping key hospital facilities open. ${ }^{100}$

The commissioners of Tennessee and Virginia provided the following assessments of each of the statutory criteria for assessing whether the benefits of the cooperative agreement outweigh the disadvantages, i.e., whether there is a net public advantage to the merger with state oversight. ${ }^{101}$

\section{A. Quality}

Tennessee noted the mixed evidence that hospital mergers improve quality, but concluded that with active supervision, quality would likely improve due to the parties' commitments to specific quality reporting measures, a $\$ 150$ million investment in a common clinical information technology platform, and formation of a physician-led clinical council. ${ }^{102}$ Virginia further noted that benefits to quality would result from Ballad Health's commitments to establish risk-based payment models rewarding quality and value and to invest $\$ 8$ million in a regional health information exchange. ${ }^{103}$

\section{B. Preservation of Hospital Facilities}

Acknowledging the economic pressures facing rural hospitals, Tennessee concluded the benefit of preservation of hospitals was likely, given the applicants' commitment to keep operating rural hospitals and offering key service lines for at least five years after closing, with ongoing commitments to continue operation of three primary acute care hospitals in the region. ${ }^{104}$ Virginia had a similar assessment and imposed further conditions on Ballad Health regarding the repurposing of hospitals and the maintenance of essential services in the affected areas. ${ }^{105}$

\section{Cost Efficiency}

Tennessee noted that the parties' projected savings from merger-related efficiencies ( $\$ 366$ million over the first five years, $\$ 95$ million in the subsequent five years) were merely estimates, and that the FTC believed these efficiencies were unlikely. The state was unwilling to credit the parties these efficiency-based savings unless they were passed on to consum- 
ers in the form of lower prices and community reinvestments. ${ }^{106}$ To increase the likelihood of this benefit occurring, Tennessee and Virginia will collect pricing data to monitor whether such savings are in fact passed on to consumers. In addition, the states required the parties to fund a total of $\$ 308$ million in community health investment over 10 years, and this commitment is not contingent upon the parties realizing cost savings. In other words, even if the parties failed to achieve the anticipated cost savings, Ballad Health is still obligated to fully fund the community health investments, which include funding for initiatives to expand access, support research and graduate medical education, improve population health, and fund a regional health information exchange. ${ }^{107}$

\section{Utilization}

Tennessee and Virginia both concluded that the parties' commitments to invest in a common clinical information technology platform and regional health information exchange will enable Ballad Health to reduce overutilization through better coordination of care and achievement of sufficient scale to engage in risk-based contracting with payers, including payments based on capitation, a percentage of premiums, accountable care arrangements, and quality-based payments. ${ }^{108}$ Virginia further required Ballad Health to enter into riskbased contracts with an increasing proportion of its commercial payers by specified deadlines as well as value-based payment arrangements with Medicaid managed care organizations. ${ }^{109}$

\section{E. Avoidance of Duplication}

Tennessee did not take a position on whether the applicants' cooperative agreement would avoid duplication of services, primarily because the goal of reducing duplication may be at odds with the goals of improving access and quality of care. ${ }^{110}$ Virginia similarly considered the avoidance of duplication to be a secondary benefit that was addressed by the parties' commitments to maintain essential services if the merging parties decide to eliminate duplicative service lines. ${ }^{111}$

\section{F. Population Health Improvement}

Securing tangible commitments to population health improvement was a driving force behind both Tennessee's and Virginia's decisions to approve the Ballad Health COPA. Tennessee observed that the "two health systems would not pursue population health improvement efforts to the necessary degree without the funding and incentives provided by the Cooperative Agreement and the issuance of the COPA." 112 These commitments included a financial commitment to invest $\$ 75$ million over 10 years for population health improvement, establishing a department and a plan for population health improvement, and reporting to the states on performance on population health metrics. ${ }^{113}$ 


\section{G. Other Benefits}

Both Tennessee and Virginia recognized several additional benefits that would result from the conditions imposed under the COPA. First are the benefits of improved access by medically underserved and low-income populations that could result from the parties' commitments to maintain or expand their existing charity care policies to provide individuals earning up to $400 \%$ of the federal poverty level with sliding-scale discounts or free services. ${ }^{114}$ Second is improved availability of services from the parties' commitments to invest $\$ 140$ million over 10 years to develop needed health care services, including $\$ 85$ million for behavioral and substance abuse services, \$27 million in children's health services, and $\$ 28$ million in rural health programs. ${ }^{115}$ Third are commitments to establish partnerships and expand investment of $\$ 85$ million over 10 years in research and graduate medical education and training. ${ }^{116}$

An additional concern of the states' governors and attorneys general was the impact of the Ballad Health merger on their workforces, including the potential loss of jobs from the merger and the downstream economic and health effects of reduced employment opportunities in the region. ${ }^{117}$ The Ballad Health entities are among the largest employers in the area, so to mitigate adverse effects on the Ballad Health employees, the states' conditions of approval contained employee protections, including a \$70 million commitment over 10 years to eliminate differences in pay and benefits among Ballad Health employees, prohibitions on terminating rural hospital employees without cause for two years, and notification to TDH and VDH of any planned workforce reduction of more than 50 employees of rural hospitals or a closure or reduction of a service line in a rural hospital. ${ }^{118}$

\section{H. Medicaid (Virginia)}

As required by its statutory criteria, Virginia assessed the benefits of approving the cooperative agreement to the state's Medicaid program. Virginia concluded that its Medicaid program would likely benefit from the applicants' commitments to contract with all Medicaid managed care organizations, participate in the Addiction and Recovery Treatment Services Program, and implement value-based payment programs with Virginia Medicaid managed care plans. ${ }^{119}$ Although the FTC opined that the parties had not explained why a merger would be necessary to continue or expand participation in Medicaid, the VDH Staff Analysis and Report noted that the parties' Medicaid commitments expand on existing commitments to participate in Medicaid programs. ${ }^{120}$

\section{Disadvantage: Impact on Payers' Negotiated Rates, Total Cost of Care ${ }^{121}$}

Acknowledging that the reduction in competition from the merger and the parties' substantial resulting market share could lead to higher total costs, both states required the applicants to commit to significant limitations on the ability to increase prices for commercial 
payers and to continue to negotiate with and contract with these private payers. ${ }^{122}$ The limits on price increases to private payers was a critical requirement of both Tennessee's and Virginia's approvals: Ballad Health agreed not to increase hospital or physician rates more than the latest CMS-approved Medicare Market basket amount plus $0.25 \%$ (for a total of $2.95 \%$ in 2018). ${ }^{123}$ For payers that do not offer a quality component in their fee schedules, Ballad Health may add an additional $1.25 \%$ adjustment (up to $4.2 \%$ in 2018).

To ensure compliance with these limits on price increases, both states require Ballad Health to annually report its price increases for payers, calculate the amounts that price increases exceed the amounts allowed under the cooperative agreement, and refund excess amounts to payers and patients. ${ }^{124}$ In addition, Ballad Health must reduce future payer rates to avoid receiving excess payments, taking into account the applicable inflation adjustment allowed under the cooperative agreement. ${ }^{125}$

In addition to the limits on rate increases for private payers, the merging parties agreed to several conditions regarding their health plan contracting and billing practices:

1. To negotiate in good faith with all payers in the service area; to not refuse to negotiate with any new payers or payers with small market shares; to resolve disputes with plans through mediation and notify TDH and VDH of any disputes; and, if mediation is unsuccessful, to resolve disputes through "final offer arbitration."126

2. To refrain from bargaining for or insisting upon anti-tiering or anti-steering clauses. ${ }^{127}$

3. To not engage in exclusive contracting with payers, including requiring that Ballad Health be the exclusive network provider to any payer as a condition of contracting with the payer; ${ }^{128}$ prohibiting any payer from contracting with other providers in the area; or prohibiting any payer from exclusively contracting with any affiliates of Ballad Health. ${ }^{129}$

4. To not engage in "most-favored nation" pricing with any payer. ${ }^{130}$

5. To not contract with payers on behalf of physicians, except for Integrated Solutions Health Network, LLC, or through a clinically integrated network agreement in compliance with antitrust laws. ${ }^{131}$

6. To limit out-of-network pricing and out-of-network balance billing of patients to two times the applicable hospital and physician inflation amounts for the first two years the system is out of network and to no more than the cooperative agreement's inflation amounts thereafter. ${ }^{132}$

7. To not own, operate, control, or license any health plan. ${ }^{133}$ 


\section{J. Disadvantage: Reduced Competition Among Professionals}

Both Tennessee and Virginia recognized that approving the merger could harm competition among physicians and ancillary service providers and adversely affect vendors that furnish goods and services to the merging hospitals. The concern is that a monopoly hospital system can control admitting and clinical privileges of independent physicians and control patient referrals within the health system and to ancillary, home, or outpatient providers. ${ }^{134}$

To mitigate these harms to competition among physicians and other providers, the states imposed the following conditions on the merging health systems:

1. It shall not require independent physicians to practice exclusively at its facilities or prohibit independent physicians from providing services outside of Ballad Health facilities. ${ }^{135}$

2. It shall not prohibit any independent physicians with privileges from participating in any health plans or provider networks. ${ }^{136}$

3. It shall not engage in exclusive contracting for physician services, except for contracts for certain hospital-based physician specialties, for a term of less than three years, as approved by the Tennessee Department of Health ${ }^{137}$ or as determined by the Ballad Health board in Virginia. ${ }^{138}$

4. It shall maintain an open medical staff at all its facilities ${ }^{139}$ and not restrict physicians' ability to see their patients admitted to a Ballad Health facility. ${ }^{140}$ In addition, Tennessee requires Ballad Health to allow its independent physicians to obtain privileges at any other hospitals and competing networks without jeopardizing privileges at Ballad Health facilities. ${ }^{141}$

5. Ballad Health shall not employ more than $35 \%$ of the physicians in any specialty, with exceptions for rural hospitals, hospital-based physicians, and exceptions approved by the Tennessee Department of Health. ${ }^{142}$ Only Tennessee requires this condition.

6.Tennessee prohibits Ballad Health from restricting the ability of vendors or suppliers from contracting with competitors or from requiring vendors to include "most-favored nation" provisions in contracts. ${ }^{143}$

\section{K. Disadvantage: Adverse Impact on Price, Quality, or Access}

Loss of competition between the health systems could threaten quality, increase prices, and reduce the availability of services because would-be competitors would no longer have to compete on quality or ensure services remain available to bargain for inclusion in health plan networks. Moreover, the increased market power of the combined entity can be used to demand substantially higher rates from payers, who can no longer build a viable provider network without Ballad Health. ${ }^{144}$

To address these adverse impacts on consumers, patients, and payers, the states imposed several conditions on the applicants that have been discussed above, ${ }^{145}$ including 
commitments (a) to continue operating key hospitals, rural hospitals, and essential services $^{146}$; (b) to track and report on quality measures, subject to state supervision ${ }^{147}$; (c) to limit price increases for private payers ${ }^{148}$; and (d) to invest $\$ 140$ million in expanded access to clinical services, including behavioral, children's, and rural health services. ${ }^{149}$ In addition, as further mitigating factors, Virginia notes the applicants' commitments to: (a) partner with the Virginia Medicaid program to implement value-based payment; (b) adopt a charity care policy that is more charitable than existing policies; and (c) include dental and vision services in Ballad Health's Rural Health Services plan. ${ }^{150}$

\section{Disadvantage: Availability of Less Restrictive Alternatives}

Both states observed that although it is possible that the benefits of the proposed cooperative agreement could be achieved through alternative arrangements less harmful to competition, the parties have failed to produce these benefits in the past. ${ }^{151}$ For example, Tennessee "question[ed] whether either health care system would actually pursue these benefits without the COPA, as they have not done so in the past." ${ }^{152}$ In the end, both states concluded that the terms and conditions of the states' COPA approvals tipped the balance of benefits and disadvantages in favor of approving the COPA, citing in particular the commitments to making substantial financial investments, improving population health, maintaining access to rural health facilities, and submitting to ongoing supervision. ${ }^{153}$

\section{Ongoing Supervision and Oversight}

The COPA process does not end with approval, but rather enters a new phase of state oversight. As noted above, active supervision is the second requirement for state action immunity from antitrust enforcement. States that approve a COPA must provide ongoing supervision and oversight of the merged entities to ensure compliance with the conditions of the COPA and to monitor whether the merger's benefits in fact outweigh the adverse effects of the loss of competition.

In the case of Tennessee's and Virginia's COPA/cooperative agreement laws, the obligation of oversight continues indefinitely, so long as the cooperative agreement remains approved. The COPAs do not expire by their own terms and could continue as long as the benefits of the cooperative agreement continue to outweigh the disadvantages. ${ }^{154}$ This part discusses the roles of each state agency to supervise the COPA and the resources necessary for the states to carry out their statutory oversight obligations.

\section{A. The Roles of Each State Agency}

\section{Tennessee}

Oversight entities. Tennessee's COPA law entrusts the TDH and the state attorney general with "active and continuing oversight of all cooperative agreements." 155 This continued oversight entails, at minimum, annual review of the COPA to determine whether the 
benefits of the cooperative agreement continue to outweigh the disadvantages from reductions in competition. ${ }^{156}$ In addition, TDH's role includes reviewing the findings of the COPA monitor (described below), making a determination of the continued existence of a public advantage or lack thereof, seeking modification of the COPA, pursuing enforcement in coordination with the state attorney general, and terminating the COPA. ${ }^{157}$ Finally, the COPA entity must update its plan of separation at least annually, and TDH must hold a public hearing in the COPA service area at least once every three years while the COPA is in effect. ${ }^{158}$

Tennessee's terms of certification for the Ballad Health COPA created a variety of additional entities to monitor compliance with the COPA: ${ }^{159}$

COPA compliance office, an internal office within Ballad Health that is the initial step for resolution of complaints of noncompliance with the COPA or terms of certification.

COPA monitor, an independent entity or consultant retained by TDH to monitor Ballad Health's COPA compliance and evaluate performance against the COPA performance index (discussed below). The COPA monitor's duties include reviewing the health system's reports, conducting audits, making recommendations, and providing an annual report to TDH. The COPA monitor will conduct much of the work on the ongoing assessment of Ballad Health's COPA compliance and performance.

Local advisory council, made up of eight to 10 community leaders who live in the area and facilitate input from residents of the service area.

Measures. Tennessee regulations require TDH to develop indices to evaluate the COPA's performance and effects on population health; access to health care services; economic effects; and other benefits based on recommendations of an advisory group. ${ }^{160}$ The terms of certification of the Ballad Health COPA provides that TDH will use an index to track ongoing public advantage, which includes four sub-indices: (a) a population health sub-index; (b) an access sub-index; (c) an economic sub-index; and (d) another sub-index (measuring quality, patient satisfaction, medical research, and education). Each sub-index-except economic, which is pass-fail-is scored on a scale of 1 to 100 , averaged, and weighted to calculate a final score for the year, which is used to evaluate whether the COPA offers a continuing public advantage. ${ }^{161}$ In its annual review, TDH reviews the health system's final score for the various indices, the economic sub-index pass-fail grade, the degree of compliance with the terms of certification, and the health system's trends in performance. ${ }^{162}$

Enforcement. If TDH determines that the benefits resulting from a COPA no longer outweigh the disadvantages attributable to the loss of competition resulting from the agreement, TDH may first seek modification of the agreement with the consent of the parties. If the modification is not obtained, TDH may terminate the COPA, subject to appeal by the COPA entity. ${ }^{163}$ The Ballad Health terms of certification describes the entity's 
obligation to notify TDH of material adverse events and noncompliance within 15 days and the corrective actions TDH can pursue, including prohibiting payment of bonuses or incentive compensation to executives, paying fines (ranging from $\$ 10,000$ to $\$ 1$ million) to the Population Health Fund, and/or modifying or terminating the COPA. ${ }^{164}$

The Tennessee attorney general has independent authority to commence investigation and enforcement actions of the COPA entity. The attorney general may subpoena witnesses and order the production of documents, seek an injunction of the COPA, and file suit to terminate the COPA if it establishes by a preponderance of the evidence that the benefits of the agreement and costs of canceling the agreement are outweighed by the disadvantages to competition attributable to the cooperative agreement. ${ }^{165}$

\section{Virginia}

Oversight entities. In Virginia, oversight over an approved cooperative agreement is entrusted to the commissioner of the Virginia Department of Health. ${ }^{166}$ Similar to Tennessee, the parties to the cooperative agreement must submit a report annually to the commissioner on compliance with the conditions to the cooperative agreement and information on its health care prices, costs, quality, and access to care. ${ }^{167}$ Unlike Tennessee's COPA monitor, VDH staff will conduct most of the analysis and oversight within the department. Internal officials and staff at VDH will be charged with directing oversight, analyzing data, building information technology systems, surveying and inspecting facilities, and coordinating with the authority, Ballad Health, TDH staff, and TDH's COPA monitor.

Measures. In her letter of approval, the commissioner of the VDH announced she would establish quantitative measures within three months of approval, by January 31, 2018. ${ }^{168}$ Virginia regulations call for the formation of a technical advisory panel to make recommendations to VDH on measures of quality, cost, and access, and to objectively assess the benefits and disadvantages of the cooperative agreement. ${ }^{169}$ The commissioner has exclusive authority whether to adopt, add, modify, or reject recommendations from the technical advisory panel. ${ }^{170}$ In addition to these quantitative measures, the entity's annual report must include: actions taken in relation to VDH's conditions of approval or the parties' commitments; changes in price, cost, quality, access, or population health status; financial information including actual costs, revenues, profits, and chargemaster (list prices); negotiated rates with nonphysician providers; and an updated plan of separation. All reports must be certified by a third-party auditor. ${ }^{171}$

Enforcement. If the commissioner of the VDH has reason to believe that the cooperative agreement no longer meets the requirements of Virginia law or the order of approval and its conditions, the commissioner will initiate an administrative proceeding to determine compliance. ${ }^{172}$ Virginia's order approving the cooperative agreement requires Ballad Health to notify the commissioner and the authority within 24 hours of any material adverse event or noncompliance with any of the conditions of the cooperative agreement. ${ }^{173}$ 
This is significantly shorter than Tennessee's 15-day notice requirement. The commissioner has authority to seek modification of the cooperative agreement with the consent of the parties to ensure compliance with the law, or the commissioner may revoke approval of the cooperative agreement upon finding that: the parties or the agreement are not complying with the terms and conditions of approval; the benefits of the agreement no longer outweigh the disadvantages attributable to the reduction in competition resulting from the agreement; the commissioner's approval was obtained based on an intentional misrepresentation or coercion of any party to the agreement; or the parties failed to pay required fees. ${ }^{174}$ Like any administrative action, the commissioner's findings and decision are subject to judicial review. Unlike Tennessee, the Virginia attorney general does not have independent authority to investigate or enforce the cooperative agreement.

\section{Coordination Between States on Supervision}

Although each state has an independent statutory duty to engage in active, ongoing supervision of the COPA/cooperative agreement, Tennessee and Virginia have coordinated to develop a uniform or nearly identical set of metrics, particularly in terms of access to care, quality, and private payer pricing. There are some variations between the states in their metrics on population health and total costs of care, but they are similar overall.

Key officials from both states' health departments indicated that they planned to continue coordinating as they had during the COPA application process for ongoing supervision, including through periodic conference calls and information sharing.

As with the initial approval, there are risks to each state if their postures on ongoing approval and supervision of the COPA were to diverge. For example, if one state were to terminate its approval of the cooperative agreement, the parties to the merger would need to initiate the plan of separation, which could undermine the ability of the health system facilities and providers in the other state to continue to meet their commitments under that state's terms of approval. Thus, officials from both states stressed the importance of ongoing communication and coordination to avoid the adverse effects of divergent state decisions on enforcement or ongoing approval.

\section{B. Resources for COPA Review and Ongoing Supervision}

Both the review and ongoing supervision of a COPA/cooperative agreement are extremely resource-intensive. States require extensive funding for staff time, public hearings, expert reports and analyses, data analytics, and information systems to engage in the thorough regulatory review and active supervision required for state action immunity. For instance, according to TDH staff, Tennessee's costs to review the Ballad Health COPA application were $\$ 2,995,545$.

The fee structure set forth in a state's COPA laws is critical to financing state COPA capacity. For example, Tennessee's COPA law provides that the parties to the COPA application are responsible for paying "all such costs" of TDH's and the state attorney general's review 
of the COPA application, preparation of the COPA and terms of certification, and ongoing active supervision, including the costs of the COPA monitor, TDH staff, and experts and consultants retained. ${ }^{175}$

By contrast, Virginia's laws at the time the Ballad Health cooperative agreement was approved only permitted VDH to charge the applicants up to $\$ 75,000$ for the department's costs of reviewing an application. ${ }^{176}$ The limitation in resources available in Virginia compared to Tennessee underscored the importance of resources and inter-state collaboration to minimize duplication. In practice, Virginia's limited fee structure meant Tennessee had greater capacity to engage in its review. The Virginia rules in place at the time similarly limited the parties' costs for ongoing annual review to $\$ 75,000 .{ }^{177}$ To overcome these resource constraints, in 2018 the Virginia General Assembly passed a bill that would lift these caps and allow VDH, like Tennessee, to charge all of the actual and reasonable costs of review, approval, and ongoing supervision to the parties to the cooperative agreement. ${ }^{178}$ The amended Virginia law also expressly authorizes the commissioner to contract with qualified experts and consultants to review applications for a cooperative agreement as well as for ongoing supervision and to charge the costs of such experts and consultants to the parties to the cooperative agreement. ${ }^{179}$ An estimate of VDH's annual costs of ongoing supervision of the Ballad Health cooperative agreement was included in the governor's proposed 2018 budget, totaling $\$ 624,518$ per year. ${ }^{180}$

In a multi-state COPA, each state has an independent duty to review, approve, and conduct ongoing supervision, so while close coordination between the states can streamline the process for the COPA entities, the compliance and reporting costs are generally multiplied by the number of states involved to fund each state's staff and resources involved in review and oversight.

\section{Policy Implications for Other States}

The experiences of Tennessee and Virginia in reviewing the Ballad Health COPA have several implications for other states considering implementing or applying a COPA law to immunize health care mergers from antitrust enforcement in exchange for ongoing active supervision.

Importance of resources. Sufficient resources are essential for states to have the capacity to engage in the rigorous review, approval, and ongoing oversight necessary for a COPA to meet legal requirements and constrain the merger's anticompetitive harms. Tennessee and Virginia provide a great example of the importance of being able to charge the merging parties for all the expenses of the state's application review and oversight. Tennessee's greater capacity in this regard proved critical and led Virginia to amend its cooperative agreement law to allow a similar fee structure to enable the state to conduct the level of active, ongoing supervision required under its law. 
Population health and rural hospitals. Both Tennessee and Virginia saw their COPA authority as a vehicle to seek improvements to population health and maintain rural hospitals in the region affected by the COPA. The states may view population health as the driving factor for approving a COPA, where the state is granting a monopoly in exchange for extensive investments in population health and concrete commitments to maintain or expand essential hospitals, services, and infrastructure. In particular, the states will hold the monopoly provider accountable for the health outcomes of the entire population of the region, not just the patients served by its facilities. The concerns of the FTC and health economists underscored the importance of de-coupling these commitments from the realization of uncertain cost savings from the merger. The Ballad Health experience illustrates how COPAs can provide states with leverage to secure binding commitments from private parties to invest in and assume responsibility for the region's population health. States may be more interested in allowing consolidation among rural providers if the larger health system will support struggling rural hospitals and commit to maintaining the region's access to key service lines.

In a multi-state COPA, coordination is key. Tennessee and Virginia saw the importance of coordinating their reviews and oversight to avoid negative spillover effects on the other state. For example, if Tennessee had approved and Virginia had not, the merging system would likely have divested its Virginia facilities, leaving these more vulnerable to closure, which in turn could harm residents in the region, drain health resources and investments from Virginia, and negatively affect employment at those facilities. The health-related and financial fortunes of the region rise and fall together, so multi-state collaboration and oversight are critical. In addition, coordination is necessary to maintain consistency between the states' conditions and measures for reporting.

Balancing specificity and flexibility in COPA conditions. States have many reasons to seek highly specific COPA conditions at approval due to statutory obligations to ensure their assessment of a net public advantage is adequately supported and to facilitate ongoing oversight and enforcement. The reality of ongoing oversight, however, may not match the specific conditions and measures initially set forth in the COPA approval, whether due to changing circumstances or inevitable course corrections. The process for ongoing oversight, therefore, needs to build in flexibility to reappraise, reassess, and adjust the COPA conditions, measures, and targets in a dynamic way that can be sustained years into the future. Thus, the state needs to balance its desire for COPA specificity at the outset with flexibility to make adjustments in the future, all while guarding against efforts by the providers to dilute or avoid compliance with COPA conditions in ways that will harm the communities they serve.

What a successful COPA looks like. Although empirical data on the effects of COPAs are lacking, states that endeavor to use a COPA as a health policy tool should assess whether the COPA is working, a critical task even years after the initial COPA approval. States should define what a successful COPA would look like. Some measures of success may 
include: (a) no closures of rural facilities; (b) maintenance or improvement of access to key health services; (c) increases in prices and overall health spending in line with comparable markets with more competition; (d) population health improvement among key metrics; and (e) clinical integration via common electronic health records, IT infrastructure, common clinical standards, and regionalization of clinical services. Notably, COPA success depends on the performance of both the COPA providers and the state oversight authorities. Failure on any of these global measures of COPA performance should trigger reassessment of whether the COPA conditions should be adjusted, whether the state needs to do more to meet its oversight and enforcement obligations, or whether the COPA should be terminated.

COPAs are risky, and states must remain vigilant. Despite the FTC's objections, states may be considering COPAs as a tool to manage the ongoing wave of health care consolidation and seek population health improvements, particularly in rural areas. The FTC acknowledges that there is insufficient data and evidence to determine whether state-granted COPAs are capable of mitigating the adverse effects on price, quality, and availability of health care services from the loss of competition between the merging health care entities. ${ }^{181}$ The experience of other states' COPAs illustrates some risks and challenges. First, the COPA party will have strong incentives to escape stringent regulatory oversight under the COPA, either through legislative repeal of the state's COPA law or by seeking exceptions, modifications, or regulatory evasion from the COPA conditions. ${ }^{182}$ Second, once a merger is consummated, it may be extremely difficult to "unscramble the eggs" and force a separation that restores competition among the parties. This underscores the importance of states' insistence on detailed and updated plans of separation to try to maintain structural separation as a viable remedy if the parties fail to comply. Third, states must understand that when the state grants a monopoly, it is embarking on a long-term commitment to supervision and must plan and budget for the resources and capacity to engage in rigorous oversight in perpetuity. Fourth, robust data collection on prices, access, population health metrics, and quality are required both for states to fulfill their statutory duties of ensuring the COPA offers a continued public benefit and as evidence of the effectiveness or ineffectiveness of COPAs as a policy tool to encourage integration while constraining the negative effects of consolidation. Finally, even with rigorous oversight, the entity may not be financially sustainable, posing the risk that conditions will be worse, not better, than before the merger.

In sum, a state-based COPA is a risky policy solution that permits formation of health care monopolies in exchange for state regulatory authority. COPAs may be particularly attractive for states to gain regulatory authority over rural or other areas that struggle to support vigorous health care competition, but a COPA is a substantial regulatory undertaking requiring significant resources and vigilance. It remains an open question whether states can successfully avoid the adverse outcomes of consolidation and reap the potential benefits in terms of population health, clinical integration, community investment, and maintenance of rural providers through COPAs, but Tennessee and Virginia are poised to try. 


\section{Notes}

${ }^{1}$ Fuse Brown EC. State Strategies to Address Rising Health Care Costs Caused by Health Care Consolidation. National Academy for State Health Policy website. September 2017. https://nashp.org/state-strategies-to-address-rising-prices-caused-by-health-care-consolidations/. Accessed June 14, 2018.

${ }^{2}$ Pew Charitable Trusts; MacArthur Foundation. State Health Care Spending: Key Findings. Philadelphia, PA: The Pew Charitable Trusts; May 2016. https://www. pewtrusts.org/-/media/assets/2016/05/state-health-care-spending.pdf. Accessed April 25, 2018.

${ }^{3}$ Cutler D, Scott Morton F. Hospitals, Market Share, and Consolidation. JAMA. 2013;310(18):1964-1970.

${ }^{4}$ Id.; Fulton BD. Health Care Market Concentration Trends in the United States: Evidence and Policy Responses. Health Aff (Millwood). 2017;36(9):1530-1538.

${ }^{5}$ Baicker K, Levy H. Coordination Versus Competition in Health Care Reform. N Engl J Med. 2013;369(9):789-791.

${ }^{6}$ Baker LC, Bundorf MK, Kessler DP. Vertical Integration: Hospital Ownership of Physician Practices Is Associated with Higher Prices and Spending. Health Aff (Millwood). 2014;33(5):756-763.

${ }^{7}$ Gaynor M, Town R. The Impact of Hospital Consolidation-Update. Princeton, NJ: Robert Wood Johnson Foundation; June 2012. http:/www.rwjf.org/content/dam/farm/reports/issue_briefs/2012/rwjf73261. Accessed April 25, 2018.

${ }^{8}$ Cooper Z, Craig SV, Gaynor M, Van Reenen J. The Price Ain't Right? Hospital Prices and Health Spending on the Privately Insured. NBER Working Paper No. 21815 (Revised May 7, 2018).

${ }^{9}$ Baker LC, Bundorf MK, Kessler DP. Vertical Integration: Hospital Ownership of Physician Practices Is Associated with Higher Prices and Spending. Health Aff (Millwood). 2014;33(5):756-763; Capps C, Dranove D, Ody C. The Effect of Hospital Acquisitions of Physician Practices on Prices and Spending. J Health Econ. 2018;59:139-152; Robinson JC, Miller K. Total Expenditures per Patient in Hospital-Owned and Physician-Owned Physician Organizations in California. JAMA. 2014;312(16):1663-1669; Neprash HT, Chernew ME, Hicks AL, Gibson T, McWilliams JM. Association of Financial Integration Between Physicians and Hospitals with Commercial Health Care Prices. JAMA Intern Med. 2015;175(12):1932-1939. 
${ }^{10}$ McWilliams JM, Chernew ME, Zaslavsky AM, Hamed P, Landon BE. Delivery System Integration and Health Care Spending and Quality for Medicare Beneficiaries. JAMA Intern Med. 2013;173(19):1447-1456; Neprash HT, Chernew ME, Hicks AL, Gibson T, McWilliams JM. Association of Financial Integration Between Physicians and Hospitals with Commercial Health Care Prices. JAMA Intern Med. 2015;175(12):1932-1939.

11 Ostrov BF. Outsiders Swoop in Vowing to Rescue Rural Hospitals Short on Hope-and Money. Kaiser Health News. June 4, 2018. https://khn.org/news/outsiders-swoop-in-vowing-to-rescue-rural-hospitals-short-on-hope-and-money/. Accessed July 1, 2018.

12 Fuse Brown EC, King JS. The Double-Edged Sword of Health Care Integration: Consolidation and Cost Control. Indiana L J. 2016;92(1):55-112.

${ }^{13}$ Federal Trade Commission. FTC Staff Notice of COPA Assessment: Request for Empirical Research and Public Comments. Nov. 1, 2017. https://www.ftc.gov/system/files/ attachments/press-releases/ftc-staff-seeks-empirical-research-public-comments-regarding-impact-certificates-public-advantage/p181200_copa_assessment_comment_notice_11-1-17.pdf. Accessed April 25, 2018.

${ }^{14}$ Bovbjerg RR, Berenson RA. Certificates of Public Advantage: Can They Address Provider Market Power? Washington, DC: Urban Institute; February 18, 2015. http://www.urban. org/research/publication/certificates-public-advantage. Accessed April 25, 2018.

${ }^{15}$ S.B. 698, General Assembly. 2015-16 Session, Session Law 2015-288 (N.C. 2015).

${ }^{16}$ FTC Comment I, at 70.

${ }^{17}$ See map of COPA Geographic Service Area, https://www.tn.gov/content/dam/tn/health/ documents/GeographicServiceArea4_ar.pdf. Accessed June 28, 2018.

${ }^{18}$ For example, the COPA in West Virginia involved the merger of Cabell Huntington Hospital and St. Mary's Medical Center, and the COPA in North Carolina to approve the merger of Mission Health in Asheville, NC, involved the merger of two acute care hospitals.

${ }^{19}$ Rife L. Lee County Prepares for Hospital Rebirth. Roanoke Times. Aug. 2, 2015. http://www.roanoke.com/business/news/lee-county-prepares-for-hospital-rebirth/article_964254e4-0905-5bf3-8b92-f4f7ea464540.html. Accessed June 14, 2018.

${ }^{20}$ Kutscher B. Wellmont Narrows Down Search for Partner System. Mod Healthc. June 11, 2014. http://www.modernhealthcare.com/article/20140611/NEWS/306119959. Accessed June 14, 2018. 
${ }^{21}$ Vozella L, Schneider GS. Virginia General Assembly Approves Medicaid Expansion to 400,000 Low-Income Residents. Washington Post. May 30, 2018. https://www.washingtonpost.com/local/virginia-politics/virginia-senate-approves-medicaid-expansion-to-400000-low-income-residents/2018/05/30/5df5e304-640d-11e8-a768-ed043e33f1dc_story.html. Accessed June 14, 2018.

${ }^{22}$ Antonisse L, Garfield R, Rudowitz R, Artiga S. The Effects of Medicaid Expansion under the ACA: Updated Findings from a Literature Review. Kaiser Family Foundation website. Published March 28, 2018. https://www.kff.org/medicaid/issue-brief/the-effects-of-medicaid-expansion-under-the-aca-updated-findings-from-a-literature-review-march-2018/. Accessed June 14, 2018; Lindrooth R, Perraillon MC, Hardy RY, Tung GJ. Understanding the Relationship between Medicaid Expansions and Hospital Closures. Health Aff (Millwood). 2018;37(1):111-120.

${ }^{23}$ County Health Rankings 2017. Robert Wood Johnson Foundation and University of Wisconsin Population Health Institute website. http://www.countyhealthrankings.org/explore-health-rankings. Accessed June 28, 2018.

${ }^{24}$ Galewitz P. In Appalachia, Two Hospital Giants Seeking State-Sanctioned Monopoly. Kaiser Health News. July 24, 2017. https://khn.org/news/in-appalachia-two-hospital-giants-seek-state-sanctioned-monopoly/. Accessed June 14, 2018.

2515 U.S.C. $\S \S 1-7,12-18$ (2012).

${ }^{26}$ Fuse Brown \& King, supra note 12.

27 N.C. State Board of Dental Examiners v. Federal Trade Commission, 135 S. Ct. 1101 (2015).

${ }^{28}$ Greaney TL. Coping with Concentration. Health Aff (Millwood). 2017;36(9):1564-1571.

29 Tennessee's COPA statute is set forth at Tenn. Code Ann. § 68-11-1301 et seq. Implementing regulations are codified at Tenn. Comp. R. \& Regs. 1200-38-01-.01 et seq.

30 Tenn. Code Ann. § 68-11-1303(a).

${ }^{31}$ The required elements and materials for a COPA application are set forth in Tenn. Comp. R. \& Regs. 1200-38-01-.02.

32 Tenn. Comp. R. \& Regs. 1200-38-01-.02.

${ }^{33}$ Tenn. Comp. R. \& Regs. 1200-38-01-.02 provides: "The Department shall require a Plan of Separation be submitted with the Application. The Plan of Separation shall be updated annually by the parties to the Cooperative Agreement. The parties shall provide an independent opinion from a qualified organization verifying the Plan of Separation can be operationally implemented without undue disruption to essential health services provided by the parties." 
${ }^{34}$ See Greaney, supra note 28, at 1565.

${ }^{35}$ Tenn. Comp. R. \& Regs. 1200-38-01-.05.

36 Tenn. Code Ann. § 68-11-1303(e); Tenn. R. \& Reg. Ch. 1200-38-01-.01. (Emphasis added.)

${ }^{37}$ All the criteria in Table 2 are listed in the COPA law for Tennessee and Virginia, unless otherwise noted.

38 Tenn. Code Ann. § 68-11-1303(e), (f)

39 Tenn. Code Ann. § 68-11-1303(f).

40 Tenn. Code Ann. § 68-11-1303(g)

${ }^{41}$ The monopoly provider could be subject to enforcement under Section 2 of the Sherman Act if it engages in unlawful conduct to maintain its monopoly or potentially to merger challenge under Section 7 of the Clayton Act. The latter may be difficult to enforce in practice due to the challenges of unwinding or breaking up a consummated merger.

${ }^{42}$ Va. Code Ann. § 15.2-5834.1.

${ }^{43}$ Va. Code Ann. $§ 15.2-5834.1$. The Virginia law on cooperative agreements provides: "To the extent such cooperative agreements ... might be anticompetitive within the meaning and intent of state and federal antitrust laws, the intent of the Commonwealth ... is to supplant competition with a regulatory program to permit cooperative agreements that are beneficial to citizens served by the Authority, and to invest in the Commissioner the authority to approve cooperative agreements recommended by the Authority and the duty of active supervision to ensure compliance with the provisions of the cooperative agreements that have been approved. Such intent is within the public policy of the Commonwealth to facilitate the provision of quality, cost-efficient medical care to rural patients."

${ }^{44}$ The localities participating in the Southwest Virginia Health Authority are all counties or cities in the LENOWISCO or Cumberland Plateau Planning District Commissions, Smyth County, Washington County, and the City of Bristol.

${ }^{45}$ Va. Code Ann. § 15.2-5384.1(C).

${ }^{46} 12$ Va. Admin. Code 5-22-70. Attorneys for the Ballad Health applicants prepared a helpful crosswalk comparing the two states' application requirement. https://www.tn.gov/ content/dam/tn/health/documents/March_3_2016_Letter_to_Allison_Thigpen.pdf.

Accessed August 6, 2018. 
4712 Va. Admin. Code 5-22-70. Subsection 14 requires the information on employed physicians, market entrants, and top-10 commercial payers. Subsection 17 requires description of the applicants' commitments.

48 Va. Code Ann. § 15.2-5384.1(E).

${ }^{49}$ Va. Code Ann. § 15.2-5384.1(F)(2).

${ }^{50}$ Va. Code Ann. § 15.2-5384.1(E).

${ }^{51}$ The practical difference between these two standards may be difficult to ascertain, but it generally means that if the agency's determination and factual findings are challenged, a reviewing court would apply a somewhat stricter standard in Tennessee than in Virginia.

5212 Va. Admin. Code $\S 5-221-90$. The implementing regulations provide that such conditions may include (1) a cap on the negotiated case-mix adjusted revenue per discharge by payer by product; (2) a commitment to return a portion of the cost savings and efficiencies gained through the cooperative agreement to residents in the participating localities through specific proposed mechanisms; (3) an agreement that the parties shall not prevent or discourage health plans from directing or incentivizing patients to choose certain providers; the parties shall not have any contractual clauses or provisions that prevent health plans from directing or incentivizing patients; (4) an agreement that the parties shall not engage in the tying of sales of the health system's services with the health plan's purchase of other services from the health system; (5) an agreement that the parties shall not restrict a health plan's ability to make available to its health plan enrollees cost, quality, efficiency, and performance information to aid enrollees in evaluating and selecting providers in the health plan; and (6) a commitment that the parties shall not refuse to include certain provisions in contracts with health plans that have been utilized in health plan contracts in other parts of the Commonwealth in order to promote value-based health care, including bundled payments, pay for performance, utilization management, and other processes that reward improvements in quality and efficiency.

53 Tenn. Comp. R. \& Regs. 1200-38-01-.05: "Prior to granting the COPA, the parties and Department will agree upon terms of certification and specific conditions that assure Public Advantage."

${ }^{54} \mathrm{VDH}$ staff indicated that the Virginia attorney general's office provided an attorney to the commissioner and VDH staff to assist with interpretation of the applicable statute and rules regarding the cooperative agreement. However, this attorney general attorney was kept separate from the attorney general's office's independent review of the competitive and economic effects of approving the merger. 
${ }^{55}$ See, for example, Commissioner John Dreyzehner, Tennessee Department of Health, Request for Information \#1, March 28, 2016. https://www.tn.gov/content/dam/tn/health/ documents/TDH_Request_for_Information_1_3_28_16.pdf. Accessed August 27, 2018. Requests for information ranged from the provision of additional information on the competitive environment, description of workforce impacts, financials, and more detailed analysis of anticipated efficiencies, proposed measures for assessing the public advantage of the proposed merger, and a more detailed plan of separation.

56 In addition to the expert reports commissioned by the TDH, the COPA applicants also obtained three expert reports from consultants, the Advisory Board and Healthy Communities Institute, to assess their capacity to implement a population health plan, and from Compass Lexcon, each submitted to TDH in April 2017. https://www.tn.gov/health/ health-program-areas/health-planning/certificate-of-public-advantage-application-proceedings.html. Accessed August 28, 2018.

${ }^{57}$ Dreyzehner JJ, Commissioner, Tennessee Department of Health, Letter Approving the Certificate of Public Advantage to Wellmont Health System and Mountain States Health Alliance, Sept. 19, 2017. https:/www.tn.gov/content/dam/tn/health/documents/Approval_Letter_granting_COPA.pdf [hereinafter "Tennessee Letter of Approval"]; Accessed August 27, 2018. Terms of Certification Governing the Certificate of Public Advantage issued to Ballad Health, approved Sept. 18, 2017. https://www.tn.gov/content/dam/tn/ health/documents/Ballad_Health_-_Terms_of_Certification_Governing_the_COPA_-_September_18_2017_-_approved_by_MSHA_Board.pdf [hereinafter "Tennessee Terms of Certification"]. Accessed August 27, 2018.

58 Letter from Terry Kilgore, Chairman, Southwest Virginia Health Authority, to Marissa Levine, Commissioner, Virginia Department of Health, Nov. 22, 2016. http://www.vdh. virginia.gov/content/uploads/sites/96/2016/11/SWHA-Recommendation-Transmittal-Letter.pdf. Accessed August 27, 2018. Southwest Virginia Health Authority, A Review of the Commonwealth of Virginia Application for a Letter Authorizing a Cooperative Agreement Filed by Mountain States Health Alliance and Wellmont Health System, Dec. 22, 2016. http://www.vdh.virginia.gov/content/uploads/sites/96/2016/11/SWHA-Cooperative-Agreement-Report-December-22-2016.pdf. Accessed August 27, 2018.

59 Virginia Department of Public Health, Cooperative Agreement: Additional/Supplemental Information Requests, Dec. 22, 2016. http://www.vdh.virginia.gov/licensure-and-certification/cooperative-agreement/additionalsupplemental-information-requests/. Accessed August 27, 2018.

${ }^{60}$ Letter from Terry Kilgore, Chairman, Southwest Virginia Health Authority, to Marissa Levine, Commissioner, Virginia Department of Public Health, Oct. 16, 2017. http://www. vdh.virginia.gov/content/uploads/sites/96/2017/10/Southwest-Virginia-Health-Authority-10-16-17.pdf. Accessed August 27, 2018. 
${ }^{61}$ Letter from Mark Herring, Attorney General, Commonwealth of Virginia, to Marissa Levine, Commissioner, Virginia Department of Public Health, Oct. 23, 2017. http://www. vdh.virginia.gov/content/uploads/sites/96/2017/10/OAGVDHProposedAgreement.pdf. Accessed August 27, 2018.

62 Marissa J. Levine, State Health Commissioner, Order and Letter Authorizing a Cooperative Agreement, (Oct. 30, 2017) [hereinafter "Virginia Order and Letter of Approval"]; Attachment 1, Staff Analysis Report and Recommendation [hereinafter "Virginia Staff Analysis Report"], Attachment 2, Conditions. http://www.vdh.virginia.gov/content/ uploads/sites/96/2017/10/Order-and-letter-authorizing-a-cooperative-agreement.pdf. Accessed August 27, 2018.

6312 Va. Admin. Code § 5-221-90.

64 Tenn. Comp. R. \& Regs. 1200-38-01-.05 (providing, "Prior to granting the COPA, the parties and Department will agree upon terms of certification and specific conditions that assure Public Advantage").

${ }^{65}$ Tennessee officials recall the stack of application materials approaching "two feet high."

${ }^{66}$ As one example, the parties, initial plan of separation was inadequately detailed. See Commissioner John Dreyzehner, Tennessee Department of Health, Request for Information \#1, March 28, 2016. https://www.tn.gov/content/dam/tn/health/documents/TDH_Request_for_Information_1_3_28_16.pdf. Accessed August 14, 2018.

${ }^{67}$ Mountain States Health Alliance and Wellmont Health System, Application to the State of Tennessee for a Certificate of Public Advantage, Feb. 16, 2016, at 46-47; Mountain States Health Alliance and Wellmont Health System, Application to Commonwealth of Virginia for a Letter Approving a Cooperative Agreement, Feb. 16, 2016, at 30.

${ }^{68}$ VDH Staff Analysis Report and Recommendation, Oct. 27, 2017, at 53.

${ }^{69}$ Virginia Staff Analysis Report, at 35.

70 Tennessee Terms of Certification, Addendum 1. See also text accompanying note 123, infra.

${ }^{71}$ Application to Commonwealth of Virginia for a Letter Authorizing a Cooperative Agreement, submitted by Mountain States Health Alliance and Wellmont Health System, Feb. 16, 2016, at 30.

${ }^{72}$ See Tennessee Terms of Certification, Addendum 1, §§ 1.2, 1.4.

${ }^{73}$ Application to Commonwealth of Virginia for a Letter Authorizing a Cooperative Agreement, submitted by Mountain States Health Alliance and Wellmont Health System, Feb. 16,2016 , at 48-49. 
74 Tennessee Terms of Certification, § 3.01, Exh. B; Virginia Order and Letter of Approval, Conditions 36.

${ }^{75}$ Tennessee Terms of Certification, § 3.04(e), Exh. D.

${ }^{76}$ FTC Public Comment, Nov. 1, 2016 [hereinafter "FTC Comment I"]; FTC Public Comment, Jan. 5, 2017 [hereinafter "FTC Comment II"]; FTC Public Comment, July 18, 2017 [hereinafter "FTC Comment III"].

77 FTC Comment I, at 5.

${ }^{78}$ FTC Comment I, at 12.

79 FTC Comment I, at 14. FTC staff calculated that the merger of Wellmont and Mountain States would result in a near monopoly, and the measure of concentration, the Herfindahl-Hirschman Index (HHI), would more than double, from 2,720 to 5,161. Mergers that result in a post-merger $\mathrm{HHI}$ greater than 2,500 and an increase of more than 200 points are presumed to be anticompetitive.

80 FTC Comment I, Part IV.

81 FTC Comment, at 22-23.

82 FTC Comment, at 29.

${ }^{83}$ FTC Comment I, Part VI.

${ }^{84}$ FTC Comment II, at 6-8.

${ }^{85}$ FTC Comment I, at 63-67; FTC Comment II, at 9.

${ }^{86}$ FTC Comment I, at 5, 67-70. Note, however, that these monopolies would no longer be shielded from federal antitrust laws by state COPAs and active state supervision. See note 31 , supra.

${ }^{87}$ Comments submitted by economists and academic experts included: Leemore Dafny et al., Comment, Nov. 21, 2016; Kenneth W. Kizer, Independent Assessment of the Proposed Merger Between Mountain States Health Alliance and Wellmont Health System, Nov. 21, 2016; Kenneth W. Kizer, Supplemental Report Regarding the Proposed Merger between Mountain States Health Alliance and Wellmont Health System, July 16, 2017; Michael Doane and Luke Froeb, Competition Economics LLC, An Economic Analysis for America's Health Insurance Plans, January 2015.

88 Dafny et al., supra note 87 , at 2.

89 See Doane \& Froeb, supra note 87 , at 1 . 
90 Id. at 2.

${ }^{91}$ Amerigroup Tennessee Inc., submission to the Tennessee Department of Health, Nov. 18, 2016, at 4-5.

92 Id. at 6 . Note that the final price commitments do apply to these payers.

${ }^{93}$ Anthem Blue Cross Blue Shield of Virginia, Submission to the Southwest Virginia Health Authority, Sept. 30, 2016.

${ }^{94}$ Anthem Blue Cross Blue Shield of Virginia, Supplemental Submission to the Southwest Virginia Health Authority, Oct. 26, 2016, at 2.

${ }^{95}$ Comment of Bristol, Johnson City, and Kingsport Chamber of Commerce, dated July 20, 2016.

${ }^{96}$ Comment of Holston Medical Group, Nov. 22, 2016.

${ }^{97}$ See Virginia Department of Health, Cooperative Agreement. Public Comment. http:// www.vdh.virginia.gov/licensure-and-certification/cooperative-agreement/public-comment/. Accessed August 23, 2018.

${ }^{98}$ Tennessee Letter of Approval, Sept. 19, 2017.

${ }^{99}$ Virginia Order and Letter of Approval, Oct. 30, 2017.

100 Tennessee Letter of Approval, at 4-8; Virginia Order and Letter of Approval, at 3.

101 These statutory criteria are listed in Part II.

102 Tennessee Letter of Approval, at 9-10; Terms of Certification, $\S 4.02$.

${ }^{103}$ Virginia Order and Letter of Approval, at 4; Virginia Staff Analysis and Report, at 8-9.

104 Tennessee Letter of Approval, at 10; Terms of Certification, $\S 4.03$.

${ }^{105}$ Virginia Order and Letter of Approval, at 3; Staff Analysis and Report, at 19-24; Attachment 2, Condition 27.

106 Tennessee Letter of Approval, at 11; Virginia Staff Analysis and Report, at 23-24.

107 Tennessee Terms of Certification, Art. III, Exh. B; Virginia Order and Letter of Approval, Attachment 2, Conditions 8, 23, 33, 34, 35, 36.

108 Tennessee Letter of Approval, at 11; Tennessee Terms of Certification, § 5.03; Virginia Order and Letter of Approval, at 4; Attachment 2, Condition 10.

109 Virginia Order and Letter of Approval, Attachment 2, Conditions 10, 11. 
110 Tennessee Letter of Approval, at 12.

${ }^{111}$ Virginia Order and Letter of Approval, Attachment 1, Staff Analysis and Report, at 2829.

112 Tennessee Letter of Approval, at 12.

113 Tennessee Terms of Certification, § 3.04; Virginia Order and Letter of Approval, Attachment 2, Condition 36.

114 Tennessee Letter of Approval, at 12-13; Terms of Certification, § 4.03; Virginia Order and Letter of Approval, at 4; Attachment 2, Condition 14.

115 Tennessee Terms of Certification, § 3.02; Virginia Order and Letter of Approval, Attachment 2, Conditions 33, 34, 35.

116 Tennessee Letter of Approval, at 13; Terms of Certification, § 3.03; Virginia Order and Letter of Approval, Attachment 2, Conditions 23, 24, 25.

117 Virginia Staff Analysis and Report, at 17.

118 Tennessee Terms of Certification, § 3.08; Virginia Order and Letter of Approval, Attachment 2, Conditions 19, 20, 21.

119 Virginia Order and Letter of Approval, at 4; Attachment 2, Conditions 46, 47.

120 Virginia Order and Letter of Approval, Staff Analysis Report, at 32.

${ }^{121}$ Virginia also must consider the effect of the cooperative agreement on the total cost of care, but the analysis of this factor is combined with effects on payers' negotiated rates, a disadvantage that both states are required to consider.

122 Tennessee Letter of Approval, at 14; Virginia Order and Letter of Approval, at 4; Staff Analysis Report, at 34.

${ }^{123}$ Tennessee Terms of Certification, § 5.02(a), Addendum 1; Virginia Staff Analysis Report, at 34-41; Revised Virginia Commitments, at 1-4.

124 Tennessee Terms of Certification, Addendum 1, $\$ 3.04$; Virginia Order and Letter of Approval, Attachment 2, Condition 5 (requiring Ballad Health to comply with all the requirements of Tennessee's Terms of Certification, Addendum 1).

$125 \mathrm{Id}$.

126 Tennessee Terms of Certification, §§ 5.02(b), 5.08; Virginia Order and Letter of Approval, Attachment 2, Condition 6. 
127 Tennessee Terms of Certification, § 5.02(e),

128 Tennessee Terms of Certification, § 5.02(d); Virginia Order and Letter of Approval, Attachment 2, Condition 7.

129 Tennessee Terms of Certification, § 5.02(g).

130 Tennessee Terms of Certification, $§ 5.02(k)$; Virginia Order and Letter of Approval, Attachment 2, Condition 42.

131 Tennessee Terms of Certification, $§ 5.02(j)$.

132 Virginia Staff Analysis Report, at 34-35; Revised Virginia Commitments, at 2.

${ }^{133}$ Tennessee Terms of Certification, $\S 5.02(I)$.

134 Tennessee Letter of Approval, at 14; Virginia Staff Analysis Report, at 45.

135 Tennessee Terms of Certification, § 5.05(a); Virginia Order and Letter of Approval, Attachment 2, Condition 30.

136 Tennessee Terms of Certification, $§ 5.05(b)$; Virginia Order and Letter of Approval, Attachment 2, Condition 31.

137 Tennessee Terms of Certification, §§ 502(h), 5.05(c).

138 Virginia Order and Letter of Approval, Attachment 2, Condition 43.

139 Tennessee Terms of Certification, § 5.05(d); Virginia Order and Letter of Approval, Attachment 2, Condition 29.

140 Tennessee Terms of Certification, § 502(i).

${ }^{141}$ Tennessee Terms of Certification, § 505(g).

142 Tennessee Terms of Certification, § 5.05(e).

143 Tennessee Terms of Certification, $§ 5.06$.

144 Virginia Staff Analysis Report, at 46.

145 Tennessee Letter of Approval, at 15; Virginia Staff Analysis Report, at 46-47.

${ }^{146}$ See discussion in Part III.D.2.

147 See discussion in Part III.D.1.

148 See discussion in Part III.D.9. 
149 See discussion in Part III.D.7, above.

150 Virginia Staff Analysis Report, at 48.

${ }^{151}$ Tennessee Letter of Approval, at 15; Virginia Order and Letter of Approval, at 5.

152 Tennessee Letter of Approval, at 15.

153 Id.; Virginia Staff Analysis Report, at 50-51.

154 Tennessee Terms of Certification, Art. I (defining the "COPA Term" as beginning on the issue date and ending when the COPA is terminated, "pursuant to its terms or the terms hereof or as permitted by Law, by the Department, [Ballad Health] or a final, non-appealable order of a court of competent jurisdiction"); Va. Code Ann. § 15.25384.1(H), 12 VAC 5-221-130; Virginia Approval Letter, at 6 (specifying that the Order of Approval shall remain in effect until revoked by the commissioner, modified, or terminated by the parties).

155 Tenn. Code Ann. § 68-11-1303(c).

156 Tenn. Code Ann. § 68-11-1303(g).

157 Tennessee Terms of Certification, Exh. F.

158 Tenn. Comp. R. \& Regs. 1200-38-01-.06.

159 Tennessee Terms of Certification, $\S 6.02$, Exh. F.

160 Tenn. Comp. R. \& Regs. 1200-38-01-.03.

161 Tennessee Terms of Certification, § 7.01(a).

162 Tennessee Terms of Certification, $§ 7.02$.

163 Tenn. Code. Ann. § 68-11-1303(g).

164 Tennessee Terms of Certification, $\S \S 604,6.05$, Exh. H. (describing fine ranges for breaches of provisions of the COPA terms).

165 Tenn. Code. Ann. § 68-11-1305.

166 Va. Code Ann. § 15.2-5384.1(G).

167 Id. More detailed requirements for the annual report are set forth at 12 Va. Admin. Code § 5-221-110.

168 Virginia Order and Letter of Approval, at 5. 
16912 Va. Admin. Code § 5-221-120.

17012 Va. Admin. Code § 5-221-100(C)(3); Virginia Order and Letter of Approval, at 6.

17112 Va. Admin. Code § 5-221-110.

172 Va. Code Ann. § 15.2-5384.1(H); Virginia Order and Letter of Approval, at 6.

173 Virginia Order and Letter of Approval, Attachment 2, Condition 17.

174 Va. Code Ann. § 15.2-5384.1(H).

175 Tenn. Code. Ann. § 68.11.1307; Tennessee Terms of Certification, § 9.05.

17612 Va. Admin. Code § 5-221-40.

17712 Va. Admin. Code § 5-221-110.

178 H.B. 663, 2018 Gen. Assemb., Reg. Sess. (Va. 2018) (signed by Governor March 19, 2018, effective July 2, 2018) (amending Va. Code Ann. § 15.2-5384.1).

179 Id.

180 Terry McAuliffe, Governor of Virginia, Executive Budget Document, proposed Dec. 18, 2017. http://publicreports.dpb.virginia.gov/rdPage.aspx?rdReport=BDOC2018_FrontPage (reintroduced by Governor Ralph Northam for 2018 Special Session). Accessed August 27, 2018.

${ }^{181}$ See FTC Staff Notice of COPA Assessment, supra note 13.

182 Vistnes GS. An Economic Analysis of the Certificate of Public Advantage (COPA) Agreement Between the State of North Carolina and Mission Health. Feb. 10, 2011. https://mountainx.com/files/copareport.pdf. Accessed June 14, 2018. 


\section{Author's Note}

Erin C. Fuse Brown, JD, MPH, is an associate professor of law at Georgia State University College of Law and a faculty member of the Center for Law, Health, and Society. The author acknowledges the helpful insights shared by Jeff Ockerman of the Tennessee Department of Health and Erik Bodin from the Virginia Department of Health. Special thanks to the reviewers who provided helpful comments to strengthen this report, including Tim Ashe, Laurie Jinkins, Kate Scarborough Mills, LaQuandra Nesbitt, Christian Soura, Joseph Thompson, and Hemi Tawarson. The conclusions in this report about the Ballad Health COPA/cooperative agreement are entirely the author's and do not reflect the official positions of the states of Tennessee or Virginia, the reviewers, or the Fund. 
Suggested Citation: Fuse Brown EC. Hospital mergers and public accountability: ennessee and Virginia employ a certificate of public advantage. Milbank Memorial Fund. September 2018. https://www.milbank.org/publications/hospital-mergers-and-publicaccountability-tennessee-and-virginia-employ-a-certificate-of-public-advantage/

\section{About the Milbank Memorial Fund}

The Milbank Memorial Fund is an endowed operating foundation that works to improve the health of populations by connecting leaders and decision makers with the best available evidence and experience. Founded in 1905, the Fund engages in nonpartisan analysis, collaboration, and communication on significant issues in health policy. It does this work by publishing high-quality, evidence-based reports, books, and The Milbank Quarterly, a peer-reviewed journal of population health and health policy; convening state health policy decision makers on issues they identify as important to population health; and building communities of health policymakers to enhance their effectiveness.

The Milbank Memorial Fund is an endowed operating foundation that engages in nonpartisan analysis, study, research, and communication on significant issues in health policy. In the Fund's own publications, in reports, films, or books it publishes with other organizations, and in articles it commissions for publication by other organizations, the Fund endeavors to maintain the highest standards for accuracy and fairness. Statements by individual authors, however, do not necessarily reflect opinions or factual determinations of the Fund.

(C) 2018 Milbank Memorial Fund. All rights reserved. This publication may be redistributed digitally for noncommercial purposes only as long as it remains wholly intact, including this copyright notice and disclaimer.

Milbank Memorial Fund

645 Madison Avenue

New York, NY 10022

www.milbank.org 